\title{
REVIEWS
}

\section{Aptamers as therapeutics}

\section{Anthony D. Keefe, Supriya Pai and Andrew Ellington}

\section{Abstract | Nucleic acid aptamers can be selected from pools of random-sequence}

oligonucleotides to bind a wide range of biomedically relevant proteins with affinities and specificities that are comparable to antibodies. Aptamers exhibit significant advantages relative to protein therapeutics in terms of size, synthetic accessibility and modification by medicinal chemistry. Despite these properties, aptamers have been slow to reach the marketplace, with only one aptamer-based drug receiving approval so far. A series of aptamers currently in development may change how nucleic acid therapeutics are perceived. It is likely that in the future, aptamers will increasingly find use in concert with other therapeutic molecules and modalities.

Oligonucleotide

A short nucleic acid; often implies generation by chemical synthesis.

\section{SELEX}

(Systematic evolution of ligands by exponential enrichment). SELEX is the process by which aptamers are discovered. A library of degenerate oligonucleotides are successively and iteratively partitioned for binding, and amplified enzymatically. Ultimately, individual members of the selected library are identified by being cloned and sequenced

\section{Aptamer}

A folded single-stranded oligonucleotide that binds to a molecular target such as a protein.
Institute for Cell and Molecular Biology, The University of Texas at Austin, 1 University Station, Austin, Texas 78712, USA. Correspondence to A.E. e-mail: andy.ellington@ mail.utexas.edu doi: $10.1038 /$ nrd3141
Nucleic acids can not only hybridize to one another based on a simple code, but can also form complex shapes that may act as scaffolds for molecular interactions and support complex formation with protein and small-molecule targets. Although this is true for biological nucleic acids ${ }^{1-4}$, it was only recently that a series of technological advances allowed the development of in vitro evolutionary methods for the discovery of additional, non-biological oligonucleotides that can bind to protein targets. Advances in DNA synthetic methods have enabled the generation of large populations of degenerate oligodeoxynucleotides, while PCR allows small numbers of molecules to be amplified into amounts that can be readily manipulated by researchers. When these two advances were iteratively coupled with the ability to partition oligonucleotides on the basis of their binding or catalytic activities, in vitro selection of functional nucleic acids (termed SELEX) was born $^{5,6}$. Nucleic acid ligands generated using SELEX have been termed aptamers, an invented Latin term that means 'to fit'. Aptamers are one of only a few classes of molecules that, like antibodies, can be crafted to bind to multiple different targets.

In a typical SELEX experiment a random sequence oligonucleotide library is synthesized that spans 20-100 residues in length, and each nucleotide is flanked by constant sequences required for enzymatic manipulation. The pool will frequently contain between $1 \times 10^{13}$ to $1 \times$ $10^{15}$ members, although it is claimed that even less diverse pools will yield useful aptamers ${ }^{7,8}$. In the case of RNA SELEX ${ }^{5,6}$, the library of single-stranded RNA molecules is prepared by the in vitro transcription of double-stranded DNA templates, usually using recombinant T7 RNA polymerase. In the case of DNA SELEX, the library of single-stranded DNA molecules is often prepared by the strand separation of double-stranded PCR products ${ }^{9}$.
Since the invention of the SELEX process around 1990 (REFS 5,6), researchers have identified high-affinity aptamers that target a broad cross-section of protein families including cytokines, proteases, kinases, cell-surface receptors and cell-adhesion molecules (TABLE 1). Although traditional SELEX methods require a soluble, pure form of the target, newer methods have been developed that target aptamers in a complex mixture such as cell-surface proteins ${ }^{10}$ and human plasma ${ }^{11}$. Structurally constrained peptides and protein domains or fragments can also be used to generate aptamers in instances for which the full protein is not available or for when targeting of aptamers to a particular protein domain or site is desired.

For therapeutic applications aptamers are frequently in competition with small molecules and antibodies. Initially, aptamers targeted to VEGF found utility in the treatment of wet macular degeneration ${ }^{12}$, in part because they had long half-lives in the ocular compartment. Aptamers that have properties more suitable for systemic administration are now being developed, primarily against targets in the bloodstream, such as thrombin, factor IXa and von Willebrand factor, or on cell surfaces such as epidermal growth factor receptor (EGFR). It may eventually be possible to use aptamers to access targets inside cells, either by delivering themselves or other drugs across membranes. In addition, the types of aptamers that can be discovered are beginning to expand, and now include agonists as well as antagonists. One aptamer has so far been marketed for therapeutic application, and a further eight aptamers are currently being evaluated in the clinic, including those comprising DNA, modified RNA and Spiegelmers. How the structural, chemical and pharmacokinetic characteristics of these and other aptamers influence their eventual clinical utility is a primary focus of this Review. 
Table 1 | Aptamers to targets of therapeutic interest

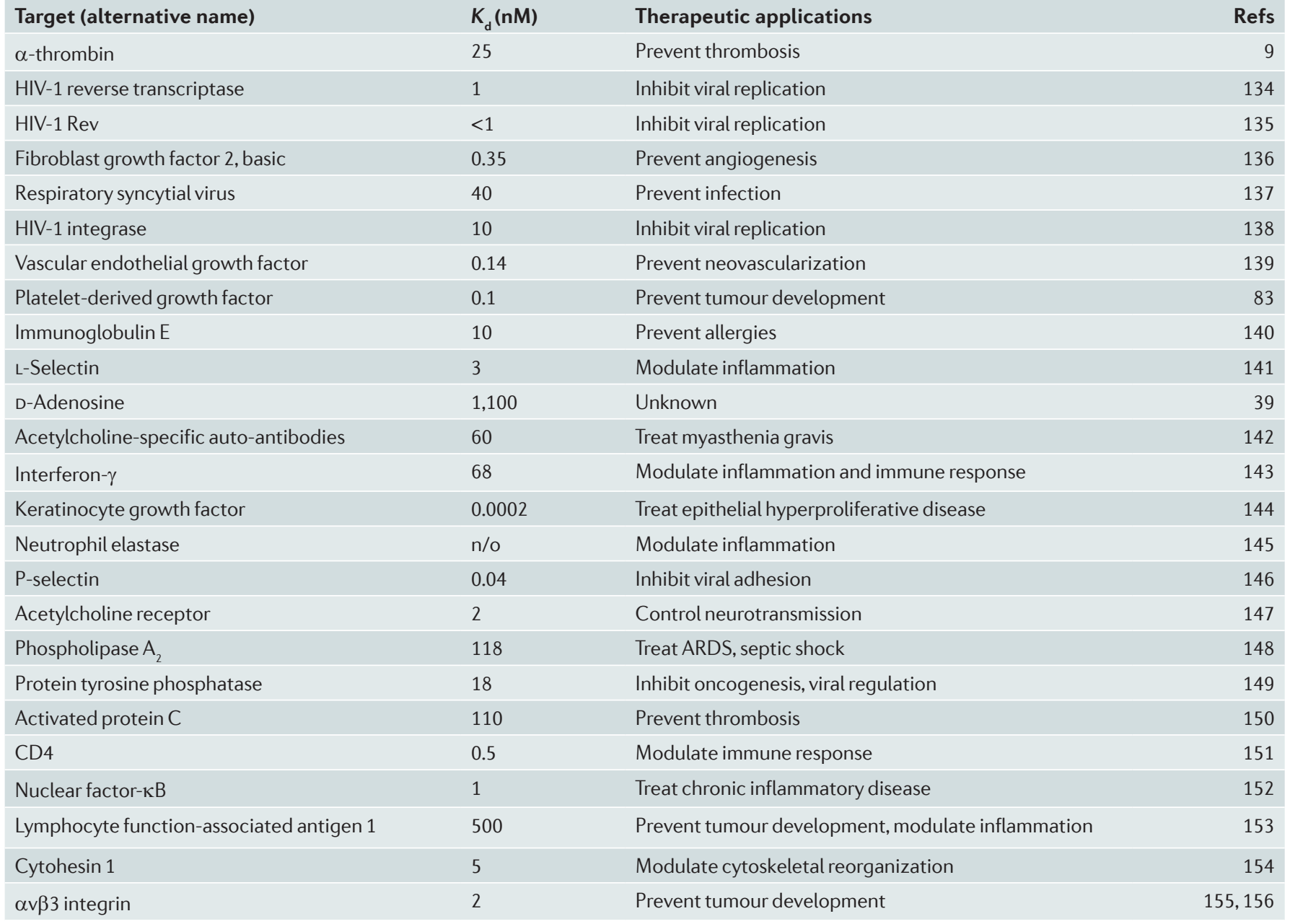

\section{VEGF}

(Vascular endothelial growth

factor). VEGF is an endogenous

pro-angiogenic protein

involved in some cancers and

in macular degeneration.

\section{Thrombin}

An activated endogenous protein that catalyses reactions leading to coagulation.

Factor IXa

An activated endogenous protein that catalyses reactions leading to coagulation.

von Willebrand factor An endogenous prothrombotic protein that recruits platelets to collagen exposed at sites of vascular injury.

\section{Spiegelmer}

An aptamer in which all of the sugars are the enantiomers (mirror image) of those found in biological nucleic acids.

\section{Therapeutic relevance of SELEX}

Aptamers as therapeutics. Aptamers can be used for therapeutic purposes in much the same way as monoclonal antibodies. However, unlike traditional methods for producing monoclonal antibodies, no organisms are required for the in vitro selection of oligonucleotides. This freedom from cellular biochemistry offers a huge advantage in manipulating the process of directed evolution. As we will see, chemistry, selection conditions and targets can be manipulated in vitro in ways that would be difficult or impossible if organisms were involved.

In addition, aptamers have a unique niche relative to other oligonucleotide therapeutics. For antisense oligonucleotides or siRNAs, the therapeutic target is intracellular, whereas aptamer therapeutics can be developed for intracellular, extracellular or cell-surface targets. Targeting proteins in these latter two classes alleviates the necessity for the therapeutic to cross the cell membrane. Much like monoclonal antibodies ${ }^{13}$, aptamers can theoretically be used therapeutically in any disease for which extracellular blockade of protein-protein interactions is required. The focus on extracellular targets has so far not been a limiting factor for aptamer development, as aptamers are currently undergoing clinical evaluation for ocular diseases, haematological diseases and cancer ${ }^{14,15}$. Some advantages and limitations of aptamers in comparison to antibodies are described in BOX 1 .

The utility of SELEX for therapeutic applications. Many aptamers that are selected to bind to a specific protein also inhibit its function. This is possibly because protein active sites offer more exposed heteroatoms for hydrogen bonding and other interactions. Another explanation is that aptamers have a limited number of interactions that they can make with a protein target, and therefore aptamers that 'fit' into a crevice on a protein, such as an active site, are more likely to be selected (the so-called homing principle).

Most therapeutically useful aptamers tend to inhibit protein-protein interactions, such as receptor-ligand interactions, and thereby function as antagonists. However, at least some aptamers have been shown to have agonist-like activities. For example, aptamers isolated against the extracellular domain of the protein human epidermal growth factor receptor 3 (HER3; also known as ERBB3) can promote oligomerization (although this does not result in inhibition of downstream phosphorylation) ${ }^{16}$. By contrast, a DNA aptamer 
Antisense oligonucleotide An agent that inhibits gene expression by cleaving specific mRNA sequences using hybridization and RNase $\mathrm{H}$.

siRNA

(Small interfering RNA) siRNA is an agent that inhibits gene expression by cleaving specific mRNA sequences using hybridization and the RNA-induced silencing complex.

Nuclease

An endogenous nucleic acid-cleaving enzyme.

Nucleotide

The phosphorylated monomeric unit of nucleic acids, comprising a base and a phosphorylated sugar. isolated against an isoleucyl tRNA synthetase enhanced editing activity ${ }^{17}$. For antagonists, therapeutic effects are only observed as long as the aptamer can physically dock with the target. If the binding affinity of the aptamer is high, it is likely that the therapeutically relevant effect will be more prolonged. Therefore, as with many other drugs, the key features of aptamers that must be optimized for drug development include high affinity and specificity, and a long half-life in the relevant biological compartment. SELEX protocols have now been developed to increase target affinity (by decreasing off-rates) and to increase specificity ${ }^{18}$. For example, specificity can be selected for by using a specific subdomain of a protein as a target, or by immobilizing the target using a specific method or affinity tag ${ }^{9}$. Iteratively toggling or switching between multiple targets during selection (for example, between the full-length protein and a specific subdomain) can drive binding to a particular epitope $\mathrm{e}^{19}$. Negative selection against closely related targets together with positive selection against the desired target can reduce cross-binding that might elicit toxicity ${ }^{20}$.
Alternatively, sequential selection against different targets can be used to ensure that aptamers cross-bind to species homologues, yielding aptamers that can be used in both animal models as well as in humans ${ }^{21}$.

In general, wild-type RNA and DNA molecules are too susceptible to nuclease-mediated degradation to be useful for most therapeutic applications. Accordingly, most SELEX experiments for therapeutics use oligonucleotides that are chemically modified in some manner. These approaches rely on DNA or RNA polymerases that can accept appropriately modified nucleotide triphosphates as substrates. Modified nucleotides can be introduced into libraries before initiation of SELEX by polymerases that can accept modified nucleotide triphosphates. This process can yield aptamers that are partially or completely substituted with one or more modifications, including $2^{\prime}$-amino pyrimidines ${ }^{22-24}$, $2^{\prime}$-fluoro pyrimidines ${ }^{25-27}$, and $2^{\prime}$ - $O$-methyl ribose purines and pyrimidines ${ }^{28,29}$ (FIG. 1 a). Internucleotide linkages can also be modified (for example, phosphorothioate linkages) $)^{30-32}$ (FIG. 1 b) and high molecular mass

\section{Table 1 (cont.) | Aptamers to targets of therapeutic interest}

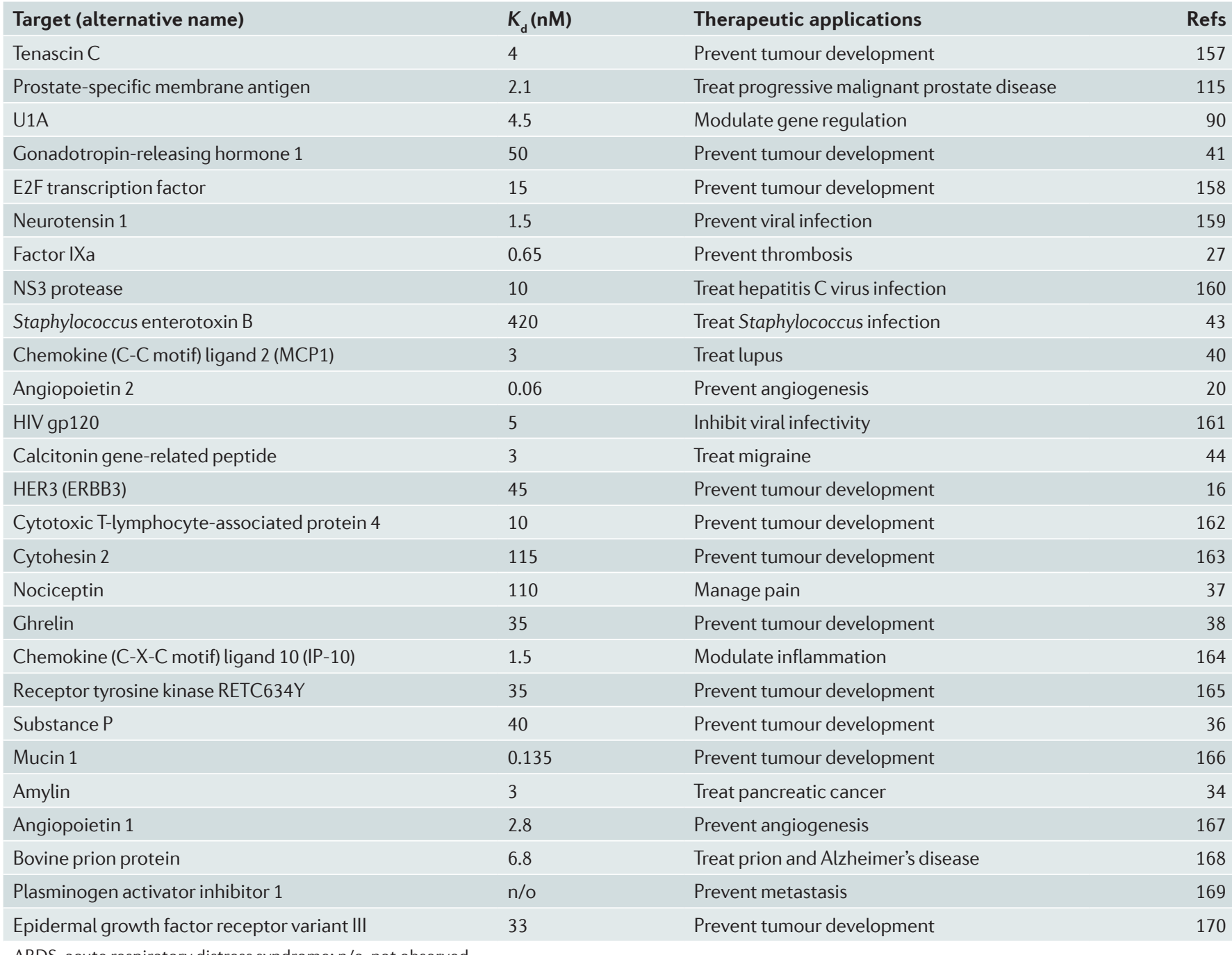


Phosphorothioate

An internucleotide

phosphodiester linkage

in which a non-bridging

oxygen is substituted

with a sulphur. polyethylene glycol (PEG) can be conjugated to the $5^{\prime}$-terminus. Finally, a wealth of chemistries are available by modifying nucleobases (for example, the 5 -position of uridine ${ }^{33}$ ). The presence of these modified nucleotides stabilizes oligonucleotides against nucleasemediated degradation, and imparts greater affinities to selected aptamers. So far, the highest affinity aptamers that have been reported in the literature contain

\section{Box 1 Advantages and limitations of aptamers versus antibodies}

\section{Advantages of antibodies}

- Pharmacokinetic and other systemic properties of antibodies are often sufficient to support product development

- Large size prevents renal filtration and together with binding to neonatal Fc receptors can give extended circulating half-lives

- Not susceptible to nuclease degradation

- Antibody technologies are widely distributed because the early intellectual property either never existed or has expired

\section{Limitations of antibodies}

- Antibodies are produced biologically in a process that is difficult to scale up without affecting product characteristics

- Viral or bacterial contamination of manufacturing process can affect product quality

- Often immunogenic

- Large size limits bioavailability or prevents access to many biological compartments

- Limited ability to utilize negative selection pressure or to select against cell-surface targets not available in functional recombinant form

- Susceptible to irreversible denaturation; limited shelf life

- Chemistries required for the attachment of conjugation partners are stochastic and lead to product mixtures and reduced activity

\section{Advantages of aptamers}

- Aptamers are produced chemically in a readily scalable process

- Chemical production process is not prone to viral or bacterial contamination

- Non-immunogenic

- Smaller size allows more efficient entry into biological compartments

- Able to select for and against specific targets and to select against cell-surface targets

- Can usually be reversibly denatured, and phosphodiester bond is extremely chemically stable

- Conjugation chemistries for the attachment of dyes or functional groups are orthogonal and can be readily introduced during synthesis

\section{Limitations of aptamers}

- Pharmacokinetic and other systemic properties are variable and often hard to predict

- Small size makes them susceptible to renal filtration and they therefore have a shorter half-life

- Unmodified aptamers are highly susceptible to serum degradation

- Aptamer technologies are currently largely covered by a single intellectual property portfolio

\section{Strategies to overcome aptamer limitations}

- Aptamers can be optimized for activity and persistence under physiological conditions during selection or during structure-activity relationship and medicinal chemistry studies conducted after discovery ${ }^{133}$

- Addition of conjugation partners such as polyethylene glycol or cholesterol can increase circulating half-life ${ }^{46}$

- Chemical modifications incorporated into the sugars or internucleotide phosphodiester linkages enhance nuclease resistance ${ }^{29}$

- Original intellectual property covering the SELEX (systematic evolution of ligands by exponential enrichment) technique will soon expire

modified nucleotides and bind in the single-digit picomolar range (see REF. 22 for an example). The choice of RNA versus DNA, and sugar, phosphate and nucleobase modifications is largely driven by the need for stability; however, a finer appreciation of how these modifications affect function is for the most part still needed. For a fuller review of this topic see REF. 18.

Spiegelmers ${ }^{34-44}$ are aptamers in which the sugars are the enantiomers (non-identical mirror images) of wildtype nucleic acid sugars. In the case of RNA Spiegelmers, the oligonucleotide backbone is composed entirely of L-riboses linked by phosphodiesters. Because nucleases are highly stereoselective these molecules are several orders of magnitude more nuclease-resistant than the corresponding wild-type RNA (D-ribose) sequences. SELEX cannot be performed with L-ribonucleotides directly because wild-type RNA polymerases will not accept L-ribonucleotide triphosphates as substrates and it is not yet technically feasible to prepare enantiomeric RNA polymerases (D-amino acids). Instead, wild-type RNA SELEX is performed using the enantiomer of the desired target. The sequences of wild-type RNA transcripts that bind to the enantiomer of the desired target, will, when prepared synthetically with L-ribose, bind to the desired target in the same manner. A significant limitation in the Spiegelmer approach is that enantiomeric targets need to be prepared synthetically, and so only relatively small protein domains or peptides can be used.

Aptamers as chemicals. Despite the fact that aptamers are discovered using an enzymatic process, aptamers are ultimately generated for therapeutic applications by chemical synthesis. Oligonucleotides are readily synthesized using solid-phase phosphoramidite chemistry in a process that has now been practiced for more than 25 years $^{45}$. This process is automated and at small scale is considered routine even for oligonucleotides of up to 100 or more nucleotides or that contain a wide range of modifications. These modifications include phosphorothioate internucleotide linkages; non-deoxyribose sugars such as ribose, 2'-fluoro-ribose and 2'-O-methyl ribose; and oligonucleotide terminal caps, such as inverted nucleotides (FIG. 1c) or cholesterol. In addition, the process of chemical synthesis allows the site-specific introduction of non-nucleotide linkers (such as hexaethylene glycol), the introduction of chemical functionalities useful for conjugation (such as primary amines, thiol precursors and aldehyde precursors), and the addition of fluorescent or other reporter moieties (FIG. 1 d). In particular, the site-specific placement of functional groups for conjugation means that the modification of aptamers after the solid-phase step (for example with high molecular mass $\mathrm{PEG}^{46}$ ) leads to products with discrete stoichiometries and defined chemical structures. These modifications avoid losses of activity that are often seen for stochastically modified therapeutic protein conjugates.

The cost of manufacturing aptamers has fallen over the past few years as the original patents in this area have begun to expire, and as the worldwide demand for oligonucleotides has driven the cost of nucleotide phosphoramidites down. At larger scales it is now possible 


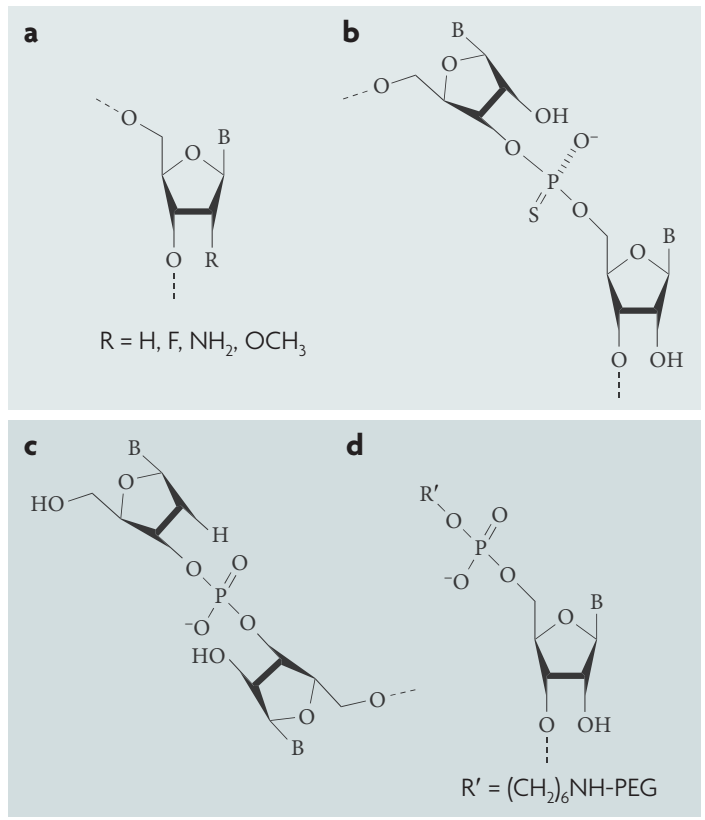

Figure 1 | Aptamer modifications. a | Nucleotides can be modified by replacing the 2' position with either a fluoro$(\mathrm{F})$, amino- $\left(\mathrm{NH}_{2}\right)$ or $\mathrm{O}$-methyl $\left(\mathrm{OCH}_{3}\right)$ group for enhanced nuclease resistance. These modified nucleotides can be introduced either chemically or enzymatically. b | Bridging phosphorothioates can be incorporated enzymatically. c| End caps that involve reversing the polarity of the chain can be incorporated during chemical synthesis. $\mathbf{d}$ | Linkers are often inserted at the $5^{\prime}$-ends of aptamers by either chemical or enzymatic means to provide handles for conjugation or to alter pharmacokinetic properties. $\mathrm{B}$, base; PEG, polyethylene glycol.

to pay less than US $\$ 3$ per gram for DNA phosphoramidites, and less than $\$ 20$ per gram for 2 '-fluoro, 2 '-ribo and $2^{\prime}$-O-methyl RNA phosphoramidites. It is relatively straightforward to acquire equipment to synthesize aptamers in the $10 \mathrm{~g}$ per batch range, and there are contract manufacturing organizations that are able to extend this to above $1 \mathrm{~kg}$ per batch. Purification is also straightforward because aptamers spontaneously refold after denaturation at elevated temperature or by chaotropic agents. These facts combine to make it much easier to advance the early stages of a therapeutic aptamer discovery project in comparison with a corresponding therapeutic antibody discovery project.

(Neonatal Fc receptor). FcRn recycles endosomal antibodies back into the extracellular space and thereby extends their circulating half-life.

Pegaptanib

Pegaptanib (trade name Macugen) is a vascular endothelial growth factor-specific aptamer approved in the United States and in Europe for the

treatment of wet age-related macular degeneration by intravitreal injection.

\section{Factors affecting therapeutic potency in vivo}

Although the selection of aptamers for therapeutic applications is relatively straightforward, the adaptation of aptamers for use in vivo has required extensive research. Relevant features of many protein therapeutics, such as those used in replacement therapies, can be extrapolated on the basis of characteristics of known, circulating proteins. For example, therapeutic antibodies tend to have long circulating half-lives because of their large molecular mass and FcRn-mediated recycling. However, there are few circulating nucleic acids from which similar comparisons can be drawn. Conversely, even though aptamers are chemicals, as outlined above, they are large by the standards of traditional non-protein drugs and do not readily cross biological barriers such as cell membranes. Thus, many of the general rules that are typically applied by medicinal chemists during drug development do not apply to aptamers.

Most targets for therapeutic aptamers are either in solution in the blood plasma or displayed on the surface of cells that are accessible from the blood plasma, such as on the surface of the vasculature. Aptamers in this medium are subject to nuclease-mediated degradation by serum nucleases, renal filtration, uptake by the liver and other tissues such as the spleen.

Nuclease resistance. Aptamers composed of unmodified nucleotides have half-lives in the blood that can be as short as 2 minutes ${ }^{47}$. As we have previously stated, chemical modifications can be incorporated into the nucleotide sugars or internucleotide phosphodiester linkages to increase serum half-life. Endogenous serum nucleases have higher degradation rates when cleaving at pyrimidine residues ${ }^{48}$ and accordingly the earliest modified composition aptamers showed considerable increases in serum stabilities even though their purines remained unsubstituted during SELEX ${ }^{24,26}$. More recently, SELEX with fully modified oligonucleotide compositions has also been reported ${ }^{28}$. Modifications can also be introduced after discovery, in a manner that is conceptually similar to small-molecule drug medicinal chemistry. Medicinal chemistry approaches can also be utilized to stabilize aptamers against nuclease-mediated degradation. Although it is laborious, aptamers can be scanned for the site-specific introduction of nuclease-resistant modifications ${ }^{26,49,50}$. The capping of oligonucleotide termini, especially at the 3 '-terminus, also increases stability to endogenous serum nucleases ${ }^{51}$. This is often accomplished by inverting the nucleotide at the $3^{\prime}$-terminus so that the oligonucleotide has two $5^{\prime}$-termini and no $3^{\prime}$-termini, as $3^{\prime}$-exonuclease activity in serum is much higher than $5^{\prime}$-exonuclease activity.

Overall, such strategies can greatly increase serum half-lives ${ }^{28}$. Together with mechanisms to avoid renal filtration (see below) highly 2'-modified aptamers that are conjugated to $40 \mathrm{kDa}$ PEG show half-lives as long as 1 day in rodents ${ }^{28}$ and 10 days in humans (see prescribing information for pegaptanib (Macugen; Pfizer/Eyetech); Further information).

Renal filtration. Most aptamers fall into the $5-15 \mathrm{kDa}$ molecular mass range (15-50 nucleotides long) and are therefore susceptible to renal filtration regardless of how well they resist nuclease-mediated degradation. As the molecular mass cutoff for the renal glomerulus is $30-50 \mathrm{kDa}$, aptamers that are conjugated to polymers in this size range show significant reduction in renal filtration rates. The most commonly used polymer for preventing exclusion by renal filtration is high molecular mass PEG ${ }^{46,52,53}$

Unconjugated aptamers clear from the mouse circulatory system with a half-life of 5-10 minutes, whereas $40 \mathrm{kDa}$ PEG-aptamer conjugates can have circulating 


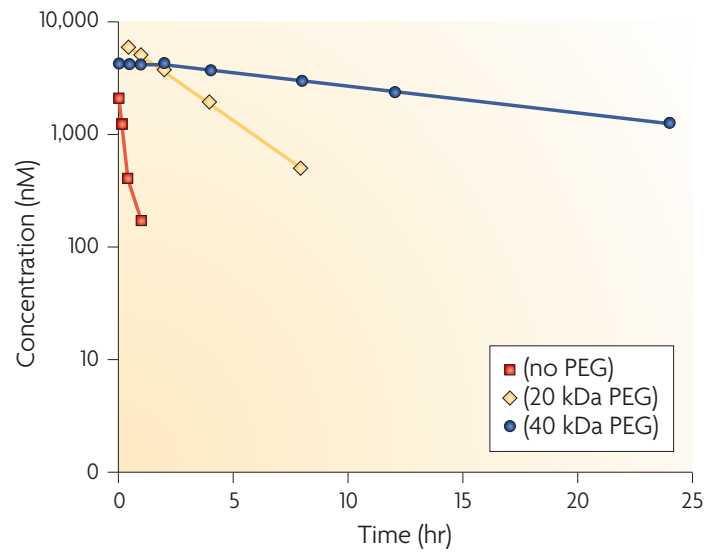

Figure 2 | The pharmacokinetics of aptamers conjugated to different molecular mass PEGs. Pharmacokinetic profiles of 39-mer 2'-deoxy purine, 2'-O-methyl pyrimidine composition aptamers. These aptamers were unconjugated or conjugated to either $20 \mathrm{kDa}$ polyethylene glycol (PEG) or $40 \mathrm{kDa}$ PEG and administered intravenously to CD-1 mice ( $n=3$ per time point) at $10 \mathrm{mg}$ per kg. Data redrawn from REF. 54.

half-lives as long as 1 day $^{28}$. The pharmacokinetic behaviours of unconjugated, $20 \mathrm{kDa}$ PEG-conjugated and $40 \mathrm{kDa}$ PEG-conjugated aptamers in the mouse after intravenous administration ${ }^{54}$ are shown in FIG. 2.

Cholesterol conjugation has also been reported as an alternative strategy to reduce renal filtration rates, although the extent of this effect seems to be less than for PEG conjugation ${ }^{55}$. Conjugation of a $40 \mathrm{kDa}$ PEG to a $2^{\prime}$ fluoro/2'-O-methyl modified aptamer increased its circulating half-life from 0.5 hours to 12 hours when administered to Sprague-Dawley rats. Moreover, a $40 \mathrm{kDa}$ PEG conjugated to a fully 2 '-O-methyl aptamer persisted in circulation with a half-life of 23 hours in mice ${ }^{28}$. In another example, Rusconi et al..$^{56}$ report the conjugation of cholesterol to a factor IXa-specific aptamer that resulted in an increase in half-life from 5-10 minutes to $1-1.5$ hours in swine. Aptamer circulating half-lives are expected to increase as the clearance rate decreases, which is in turn proportional to the mass of the animal raised to the power of 0.75 (REF. 57). Consequently, longer half-lives are expected to be observed for animals larger than rodents.

Aptamers may be particularly amenable to modifications that lead to improved pharmacokinetic properties. Protein-PEG conjugation is generally performed stochastically through lysine side chains and this often results in a mixture of products and a loss of activity. By contrast, as aptamers are chemically synthesized and lack many of the functional groups commonly present in proteins, a single functional group (such as an alkyl amine) can be site-specifically introduced and used as a unique site for conjugation of other molecules to the aptamer without disrupting structure or function. Such site-specific handles for conjugation can be scanned through a number of positions to ensure that conjugation to PEG does not affect the activity of the conjugate.
Toxicology. As with other therapeutics, aptamer toxicity can manifest itself through on-target or off-target mechanisms. Off-target effects of oligonucleotides have previously been extensively studied as part of the development of antisense oligonucleotide therapeutics, and include anticoagulation, complement activation and innate immune stimulation. Antibodies to synthetic oligonucleotides are not generally observed, but have been seen for some oligonucleotide conjugation partners such as $\mathrm{PEG}^{58}$. There is limited published information concerning the toxicological properties of aptamer therapeutics because so far there is only one approved aptamer drug (pegaptanib), which is administered in small doses by intravitreal injection. However, there is literature concerning the toxicology of antisense therapeutics because this modality is a more mature research topic; reviews include REFS 59-61. Antisense oligonucleotide therapeutics and aptamer therapeutics differ in several respects including chemical substitution, size, secondary structure and conjugation to PEG; however, some parallels can be drawn.

Innate immune activation occurs as a consequence of the activation of Toll-like receptor 3 (TLR3), TLR7, TLR8 or TLR9. TLR3 responds to double-stranded RNA, TLR7 and TLR8 respond to single-stranded RNA, and TLR9 responds to unmethylated CG motifs in DNA (CpG motifs). Because unmodified RNA is highly sensitive to endogenous nucleases and because 2 '-modification abrogates the TLR response ${ }^{62}$, it is probably TLR9 that is most relevant to the study of potential adverse effects of therapeutic aptamers, although other TLRs may be relevant to the interpretation of in vivo responses to siRNA. Innate immune responses mediated by TLR9 include the activation of antigen-specific B cells and the secretion of cytokines including interleukin- 6 and interferon ${ }^{63,64}$. Nevertheless, TLR9-mediated immune responses to oligonucleotides are being considered for therapeutic applications in which immune stimulation is desirable such as in oncology ${ }^{65}$.

Anticoagulation has been observed in primates after administration of oligonucleotides. It is thought that this is a consequence of low-affinity interactions between the oligonucleotide and protein components of the clotting cascade. Many of these proteins bind to heparin and therefore might be expected to bind to other polyanions such as oligonucleotides. Measurable effects on clotting times have been observed using activated partial pro-thromboplastin time assays ${ }^{66}$. This effect is probably not significant enough to be of concern to patients as increases in bleeding times have not been reported.

Complement activation has been attributed to the interaction of oligonucleotides with complement factor $\mathrm{H}$, which is a control protein for the alternative complement pathway. Complement activation has been observed in studies conducted in nonhuman primates in which effects are predominantly acute and seem to manifest themselves only after a high oligonucleotide concentration has been reached. Observations include hypotension and elevated heart rate, and can include cardiovascular collapse when severe ${ }^{60}$. 


\begin{tabular}{|c|c|c|c|c|c|}
\hline $\begin{array}{l}\text { Name } \\
\text { (company) }\end{array}$ & Composition & Target & Indication & $\begin{array}{l}\text { Current } \\
\text { phase }\end{array}$ & Refs \\
\hline $\begin{array}{l}\text { Pegaptanib } \\
\text { sodium/Macugen } \\
\text { (Pfizer/Eyetech) }\end{array}$ & $\begin{array}{l}\text { 2'-O-methyl } \\
\text { purine/2'-fluoro pyrimidine } \\
\text { with two 2'-ribo purines } \\
\text { conjugated to } 40 \mathrm{kDa} \text { PEG, } \\
\text { 3' inverted dT }\end{array}$ & $\begin{array}{l}\text { Vascular } \\
\text { endothelial } \\
\text { growth factor }\end{array}$ & $\begin{array}{l}\text { Age-related macular } \\
\text { degeneration }\end{array}$ & $\begin{array}{l}\text { Approved in } \\
\text { the US and } \\
\text { the EU }\end{array}$ & $12,69,70$ \\
\hline $\begin{array}{l}\text { AS1411/ } \\
\text { AGRO001 } \\
\text { (Antisoma) }\end{array}$ & G-rich DNA & Nucleolin & $\begin{array}{l}\text { Acute myeloid } \\
\text { leukaemia }\end{array}$ & Phase II & $71,72,74$ \\
\hline $\begin{array}{l}\text { REG1/RB006 } \\
\text { plus RB007 } \\
\text { (Regado } \\
\text { Biosciences) }\end{array}$ & $\begin{array}{l}\text { 2'-ribo purine/2'-fluoro } \\
\text { pyrimidine (RB006)/40 } \\
\text { kDa PEG plus 2'-O-methyl } \\
\text { antidote (RB007) }\end{array}$ & $\begin{array}{l}\text { Coagulation } \\
\text { factor IXa }\end{array}$ & $\begin{array}{l}\text { Percutaneous } \\
\text { coronary } \\
\text { intervention }\end{array}$ & Phase II & 62,63 \\
\hline $\begin{array}{l}\text { ARC1779 } \\
\text { (Archemix) }\end{array}$ & $\begin{array}{l}\text { DNA and 2'-O-methyl with } \\
\text { a single phosphorothioate } \\
\text { linkage conjugated to } 20 \\
\text { kDa PEG, 3' inverted dT }\end{array}$ & $\begin{array}{l}\text { A1 domain of von } \\
\text { Willebrand factor }\end{array}$ & $\begin{array}{l}\text { Thrombotic } \\
\text { microangiopathies } \\
\text { and carotid artery } \\
\text { disease }\end{array}$ & Phase II & 64,65 \\
\hline $\begin{array}{l}\text { NU172 (ARCA } \\
\text { biopharma) }\end{array}$ & Unmodified DNA aptamer & Thrombin & $\begin{array}{l}\text { Cardiopulmonary } \\
\text { bypass to maintain } \\
\text { steady state of } \\
\text { anticoagulation }\end{array}$ & Phase II & 66 \\
\hline $\begin{array}{l}\text { ARC1905 } \\
\text { (Ophthotech) }\end{array}$ & $\begin{array}{l}\text { 2'-ribo purine } / 2^{\prime} \text {-fluoro } \\
\text { pyrimidine conjugated to } 40 \\
\text { kDa PEG, } 3 \text { ' inverted dT }\end{array}$ & $\begin{array}{l}\text { Complement } \\
\text { component } 5\end{array}$ & $\begin{array}{l}\text { Age-related macular } \\
\text { degeneration* }\end{array}$ & Phase I & 67 \\
\hline $\begin{array}{l}\text { E10030 } \\
\text { (Ophthotech) }\end{array}$ & $\begin{array}{l}\text { DNA and 2'-O-methyl } \\
5^{\prime} \text {-conjugated to } 40 \mathrm{kDa} \\
\text { PEG, 3' inverted dT }\end{array}$ & $\begin{array}{l}\text { Platelet-derived } \\
\text { growth factor }\end{array}$ & $\begin{array}{l}\text { Age-related macular } \\
\text { degeneration* }\end{array}$ & Phase I & 68 \\
\hline $\begin{array}{l}\text { NOX-A12 } \\
\text { (NOXXON } \\
\text { Pharma) }\end{array}$ & L-RNA with 3'-PEG & CXCL12 & $\begin{array}{l}\text { Multiple myeloma } \\
\text { and non-Hodgkin's } \\
\text { lymphoma }^{\ddagger}\end{array}$ & Phase I & 84 \\
\hline $\begin{array}{l}\text { NOX-E36 } \\
\text { (NOXXON } \\
\text { Pharma) }\end{array}$ & L-RNA with 3'-PEG & CCL2 & $\begin{array}{l}\text { Type } 2 \text { diabetes, } \\
\text { diabetic } \\
\text { nephropathy }\end{array}$ & Phase I & $40,85,86$ \\
\hline
\end{tabular}

Oligonucleotides have also been observed to accumulate in cells. This can be observed qualitatively by immunohistochemistry, in situ hybridization or the histopathology of stained tissue $e^{59,67}$. The accumulated material is generally seen in phagocytes such as macrophages or in renal proximal tubule epithelial cells. Degenerative effects have also been observed at high doses ${ }^{68}$. It is also possible that particular mechanisms of accumulation could be exploited for therapeutic applications, as described below.

\section{Aptamers in the clinic}

There are now several aptamers that have undergone clinical trials (TABLE 2), and a consideration of the observations that have been made in these trials will provide a better understanding of both the possibilities and limitations of aptamers as therapeutics. These will be discussed below.

Pegaptanib. Pegaptanib ${ }^{69}$ was approved for therapeutic use by the US Food and Drug Administration in December 2004 and is currently marketed by Pfizer and Eyetech as Macugen. Pegaptanib is a VEGF-specific aptamer that binds to all isoforms of human VEGFA except for the smallest (VEGF121). Once pegaptanib is bound to VEGF it inhibits the interaction of VEGF with its receptors VEGFR1 (also known as FLT1) and VEGFR2 (also known as KDR/ $\mathrm{FLK1}$ ), with an $\mathrm{IC}_{50}$ value of $49 \mathrm{pM}^{26}$. Pegaptanib was originally discovered in a 2 '-ribo purine/2'-fluoro pyrimidine (rRfY) transcript library using SELEX. Once selected, the aptamer was truncated to 27 nucleotides to decrease synthesis costs, and then 12 out of the 14 ribopurines were replaced with 2'-O-methyl purines to increase nuclease resistance. The oligonucleotide was then conjugated to $40 \mathrm{kDa}$ PEG to reduce the rate with which it distributes into tissues and it also was capped at the $3^{\prime}$-terminus with an inverted nucleotide to reduce $3^{\prime}$-exonuclease-mediated degradation. Pegaptanib is administered by intravitreal injection of $0.3 \mathrm{mg}$ per eye once every 6 weeks, and is used to ameliorate the loss of visual acuity that is caused by the aberrant angiogenesis that is characteristic of age-related macular degeneration (AMD) ${ }^{70}$. Although pegaptanib sold well after regulatory approval, it has more recently lost significant market share to the antibody fragment ranibizumab (Lucentis; Genentech), which binds to all isoforms of human VEGFA including VEGF121. 
AS1411. AS1411, formerly AGRO001, is a G-rich 26-mer oligodeoxynucleotide that contains only guanines and thymines and exists in solution as a guanine-quartetmediated dimer. AS1411 is thought to elicit its therapeutic effects through its interaction with nucleolin ${ }^{71}$. AS1411 was discovered as part of a screen of antisense oligonucleotides for antiproliferative activity ${ }^{72}$. In common with other therapeutics discovered by cell-based screening (as opposed to screening or selection against individual protein targets) it is less certain what its exact mechanism of action is. Various biochemical effects have been demonstrated for this molecule including the destabilization of B-cell lymphoma protein 2 (BCL-2) $\mathrm{mRNA}^{73}$, the inhibition of nucleolin-containing complexes $^{74}$ and the inhibition of nuclear factor- $\mathrm{KB}^{75}$. AS1411 inhibits the proliferation of cells in a wide range of cancer cell lines. The suggested mechanism of action for the antiproliferative activity of AS1411 includes binding to, and subsequent internalization by, cell-surface nucleolin followed by binding to cytoplasmic nucleolin. AS1411 is being developed by Antisoma and is currently in Phase II clinical trials for acute myeloid leukaemia, but it has recently been decided not to continue clinical evaluation of AS1411 for renal cancer ${ }^{76}$.

REG1. REG1 is an anticoagulation system that includes RB006, a coagulation factor IXa-specific aptamer, and its oligonucleotide antidote RB007. REG1 is currently being evaluated in the clinic as a reversible anticoagulant for use during percutaneous coronary intervention ${ }^{77}$. RB006 was discovered in a 2'-ribo purine $/ 2^{\prime}$-fluoro pyrimidine transcript library using SELEX ${ }^{27}$. The aptamer was then truncated to 34 nucleotides, conjugated to $40 \mathrm{kDa}$ PEG to reduce the rate with which it is cleared from the serum by renal filtration and capped at the $3^{\prime}$-terminus with an inverted nucleotide to reduce $3^{\prime}$-exonuclease-mediated degradation. RB006 binds to coagulation factor IXa with an equilibrium dissociation constant $\left(K_{\mathrm{d}}\right)$ of $2.8 \mathrm{nM}$ and prolongs clotting times as assessed in activated partial thromboplastin time assays. It does not prolong the clotting time of plasma when measured in prothrombin time assays, which is as expected for a specific coagulation factor IXa inhibitor. RB007 is a fully 2'-O-methyl substituted 17 -mer oligonucleotide that is complementary to the $5^{\prime}$-terminal region of RB006. RB007 rapidly disrupts the structure of RB006 and inhibits its anticoagulation function. REG1 is being developed by Regado Biosciences. It is currently in Phase II clinical trials and shows rapid onset of anticoagulation in vivo after intravenous administration, followed by a rapid return to baseline levels after dosing of the RB007 antidote ${ }^{78}$.

ARC1779. ARC1779 binds to the A1 domain of von Willebrand factor ${ }^{19}$ and inhibits the capacity of this domain to bind to platelet membrane glycoprotein $\mathrm{Ib}$ receptors, thereby eliciting an antithrombotic effect without significant anticoagulation ${ }^{79}$ (FIG. 3). ARC1779 was discovered in a degenerate DNA library using SELEX and then truncated to 39 nucleotides. It was also substituted with a single phosphorothioate linkage to increase target affinity and $5^{\prime}$-conjugated to $20 \mathrm{kDa}$ PEG to reduce the rate with which it is subject to renal filtration. Additional alterations included capping at the 3 '-terminus with an inverted nucleotide, and 26 2'-O-methyl modifications were introduced to increase nuclease resistance and thermal stability. ARC1779 binds to von Willebrand factor with a $K_{\mathrm{d}}$ value of $2 \mathrm{nM}$ and inhibits platelet function with an $\mathrm{EC}_{90}$ value of $196 \mathrm{nM}^{80}$. ARC1779 is being developed by Archemix and is currently in Phase II clinical trials for thrombotic microangiopathies and in patients with carotid artery disease undergoing carotid endarterectomy.

NU172. NU172 is a 26-mer oligodeoxynucleotide that is not modified, capped or conjugated and binds to and inhibits thrombin by an interaction with exosite 1. NU172 was discovered within a degenerate DNA oligonucleotide library using SELEX and was subsequently truncated to 26 nucleotides. It has an $\mathrm{IC}_{50}$ value of 5-10 $\mu \mathrm{g}$ per $\mathrm{ml}$ in plasma in an ecarin clotting time assay as measured by thromboelastography ${ }^{81}$. This aptamer is currently being evaluated in Phase II clinical trials by ARCA Biopharma. Because NU172 is not capped, substituted or conjugated to PEG, it has a short duration of action in vivo. NU172 is intended to be given by continuous infusion during cardiopulmonary bypass or other surgical procedures to maintain a state of anticoagulation with a rapid return to haemostasis once the infusion ceases.

ARC1905. ARC1905 binds to complement component 5 (C5), which is thought to play a role in AMD because it is pro-inflammatory and has been found in retinal deposits of patients with $\mathrm{AMD}^{82}$. ARC1905 was discovered in a 2 '-ribo purine/2'-fluoro pyrimidine transcript library using SELEX. It was truncated to 39 nucleotides, $5^{\prime}$-conjugated to $40 \mathrm{kDa}$ PEG to reduce the rate with which it is subject to renal filtration and capped at the 3 '-terminus with an inverted nucleotide ${ }^{25}$. ARC1905 binds to C5 with a $K_{\mathrm{d}}$ value of 2-5 nM. ARC1905 is being developed by Ophthotech and is currently in Phase I clinical trials in which it is co-dosed with the VEGF-specific antibody fragment ranibizumab by intravitreal injection.

E10030. E10030 binds to platelet-derived growth factor (PDGF), which is known to play a role in the recruitment and maturation of pericytes that can increase resistance to the anti-VEGF treatment of AMD. E10030 was discovered in a degenerate DNA library using SELEX and then truncated to 29 nucleotides. Further engineering efforts included $5^{\prime}$-conjugation to $40 \mathrm{kDa}$ PEG to reduce the rate with which it is subject to renal filtration and capping at the 3 '-terminus with an inverted nucleotide. In addition, it was substituted with seven 2 '-fluoro nucleotides and five 2'-O-methyl nucleotides to reduce nuclease degradation rates, and it has hexa ethylene glycol linkers in place of loops within the oligonucleotide structure ${ }^{83}$. E10030 is being developed by Ophthotech and is currently in Phase I clinical trials for AMD in which it is co-dosed with the VEGF-specific antibody fragment ranibizumab by intravitreal injection. 


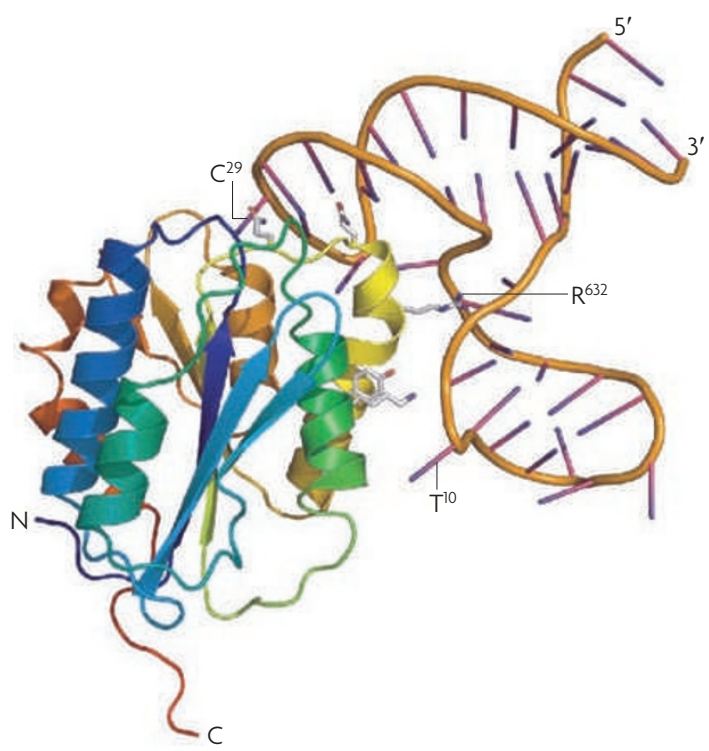

Figure 3 | Crystal structure of the all-DNA parent of ARC1779 bound to the A1 domain of von Willebrand factor.

NOX-A12. NOX-A12 binds to chemokine (C-X-C motif) ligand 12 (CXCL12; also known as SDF-1 $\alpha$ ), which is a chemokine thought to have multiple roles in cell homing, tumour metastasis, angiogenesis and tissue regeneration. NOX-A12 binds its target with an affinity of less than $1 \mathrm{nM}$, has an $\mathrm{IC}_{50}$ value of $300 \mathrm{pM}$ in a Jurkat cell migration assay, and significantly reduces glomerulosclerosis in a mouse model of type 2 diabetes $^{84}$. NOX-A12 is an L-RNA aptamer (Spiegelmer) that is 45 nucleotides long and has no chemical modifications beyond the reversed stereochemistry of the sugars and a high molecular mass PEG at the $3^{\prime}$-terminus. NOX-A12 was selected from a wild-type (D-RNA) library using the mirror-image target (D-amino acids), but was ultimately synthesized as an L-RNA in order to bind the wild-type target ( $\mathrm{L}$-amino acids). NOX-A12 is being developed for use with autologous haematopoietic stem cell transplants, as inhibition of CXCL12 affects the homing, mobilization and retention of these cells. It is intended to be used in the treatment of multiple myeloma or non-Hodgkin's lymphoma. NOX-A12 is being developed by NOXXON Pharma and is currently being evaluated in a Phase I clinical trial in which it is administered intravenously.

NOX-E36. NOX-E36 binds to chemokine (C-C motif) ligand 2 (CCL2; also known as MCP1), which is a protein that recruits monocytes and $\mathrm{T}$ cells from the vascular compartment to the extravascular space at sites of inflammation. NOX-E36 binds its target with an affinity of $150 \mathrm{pM}$ and has an $\mathrm{IC}_{50}$ value of $3 \mathrm{nM}$ in a mCCL2stimulated migration assay. It has shown activity in a mouse model of lupus nephritis ${ }^{85}$. Like NOX-A12, NOX-E36 is an L-RNA aptamer (Spiegelmer) that is 40 nucleotides long and has no chemical modifications beyond the reversed stereochemistry of the sugars and a high molecular mass PEG at the $3^{\prime}$-terminus ${ }^{40,85-87}$. NOX-E36 is currently being developed for the treatment of complications of type 2 diabetes, including diabetic nephropathy, by NOXXON Pharma. It recently completed evaluation in a Phase I clinical trial in which it was administered both intravenously and by subcutaneous injection.

\section{The future of SELEX and aptamers}

Advanced methods for aptamer discovery. Although high-affinity aptamers can be selected against numerous targets, the selection method itself is often labour intensive and time consuming. To further advance the number and types of aptamers available for therapeutic applications, it will be necessary to develop selection methods that are more high-throughput and to ensure that selected aptamers have exceedingly high affinities and are, or can be engineered to be, resistant to degradation and clearance. There have been several approaches to these goals.

One option is to automate the selection process so that aptamers can be reproducibly generated. In an early study, the adaptation of aptamer selection protocols to liquid-handling robots was attempted ${ }^{88}$. At a rate of 12 rounds of selection every 2 days, successful selections were achieved in just under 1 week $^{89}$. Aptamers have also been robotically selected against a human protein, U1A, coordinately produced in vitro ${ }^{90}$. The Klussmann group at NOXXON Pharma took automation a step further by directly monitoring PCR and quantifying the amount of nucleic acid bound to the target ${ }^{36}$. Although these modifications decreased the speed of automated selection, there were also improvements in the separation of RNA from salts, buffers and urea, and a concomitant decrease in PCR artefacts.

Affinity capture onto magnetic beads is also amenable to miniaturization ${ }^{91,92}$, and using picomolar amounts of targets aptamers with dissociation constants as low as $25 \mathrm{nM}$ were selected. However, the most extensive work that has been done with high-throughput discovery methods for aptamers is that by the company Somalogic, where investigators recently reported the selection of 498 aptamers and their use to simultaneously interrogate blood samples ${ }^{93}$. Somalogic has pioneered the use of modified bases for SELEX, as opposed to just modified sugars (for example, 2'-O-methyl) or modified internucleotide linkages (for example, phosphorothioate). It is likely that their success in identifying multiple, highaffinity aptamers against many different targets is in part due to the fact that they have capitalized on the dizzying range of modifications at the 5-position of uridine originally developed and reported by Eaton's group ${ }^{33,94-96}$.

Most reported initiatives that try to streamline the discovery process of therapeutic aptamers focus only on the selection and amplification steps. Although it is possible that microelectromechanical systems ${ }^{91}$, deep sequencing ${ }^{97}$ or computational prediction ${ }^{98}$ will accelerate the identification of aptamers, it seems likely that 'analogue' predictions (selection itself) will greatly outperform such efforts for some time to come. In any event, once selection is complete the library is cloned 
a

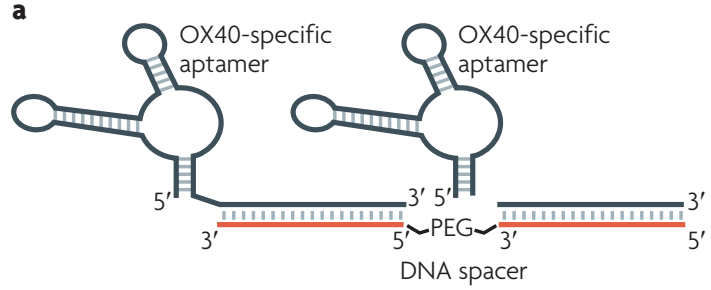

b
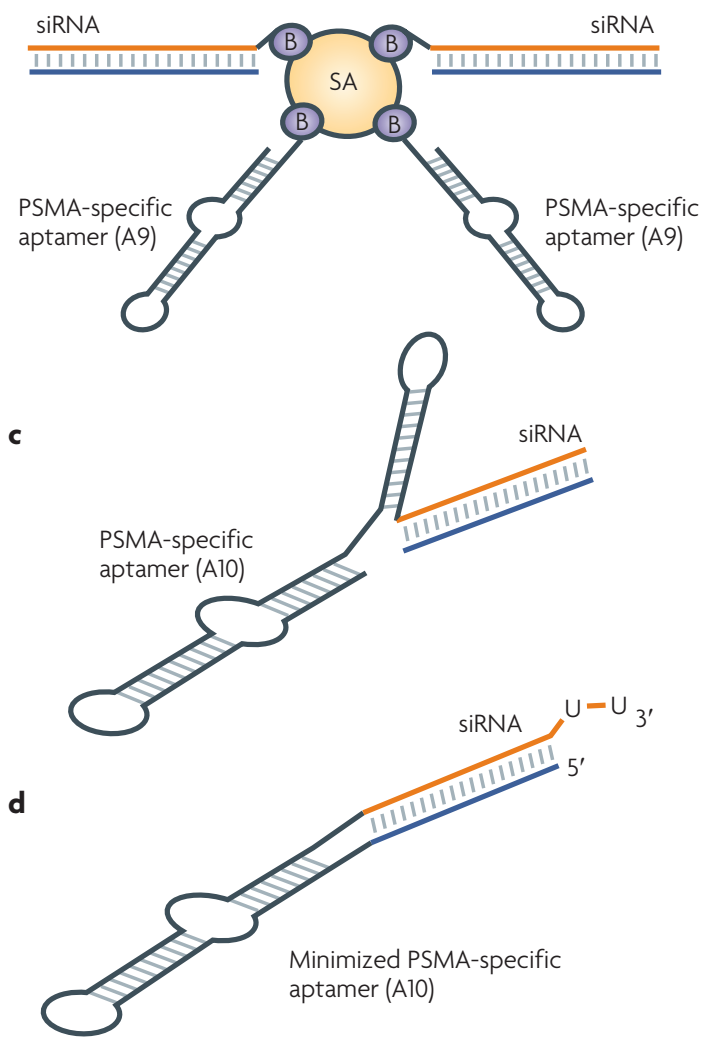

Figure 4 | Aptamer architectures for therapy. a |OX40-specific aptamers were hybridized to an 'organizer' consisting of two antisense oligonucleotides separated by a polyethylene glycol (PEG) spacer ${ }^{108,109}$. b | Prostate-specific membrane antigen (PSMA)-specific aptamer A9 and 27-mer small interfering RNAs (siRNAs) were biotinylated $(\mathrm{B})$ and conjugated to streptavidin $(\mathrm{SA})^{124}$.c | PSMA-specific aptamer A10 was extended with a sequence that promoted hybridization to the guide strand of a siRNA ${ }^{125}$. The processed extension of the aptamer can then participate in gene silencing. $\mathbf{d}$ |PSMA-specific aptamer A10 was extended with a short hairpin RNA-like sequence. Processing again leads to gene silencing ${ }^{126}$.

and sequenced, and multiple individual clones are assessed for binding to, and inhibition of, the desired target protein. Clones are ranked and this is followed by the truncation of the best performing aptamers, often dispensing with flanking sequence elements or internal loops that are not required for function. This is in turn followed by structure-activity relationship analyses in which the introduction of individual sequence or chemical substitutions yields variants that may have improved nuclease resistance and inhibitory activity. Finally, conjugation of the aptamer to PEG or cholesterol leads to reduced renal filtration rates in animal models in which therapeutic potency is ultimately assessed. However, there has been very little reported work done to try to streamline these latter steps and any further attempts to improve SELEX will, even if successful, still mean that the entire discovery process is protracted and laborious.

One exception to this generalization may be the advent of complex target SELEX, in which aptamers are directly selected against cells or even in organisms ${ }^{99-101}$. Although cell-based selection can result in cross-reacting aptamers ${ }^{102}$, many of the cell-specific aptamers generated so far have served well as internalizing escorts, neutralizing ligands or real-time imaging probes ${ }^{99,102-104}$. Particularly impressive examples of selections against organismal targets include the isolation of potent aptamers against infection-causing African trypanosomes ${ }^{105}$, and a recent selection against intrahepatic carcinomas in a mouse model by the Clary group at the Duke University Medical Center, North Carolina, USA ${ }^{106}$. In the work done by the Clary group, modified RNA pools were intravenously injected into tumour-bearing mice and aptamers that were localized to the tumours were extracted and amplified. Two selected aptamers were found to target a biomarker (P68) that was overexpressed in the tumour.

Exploiting aptamer hybridization. One of the unique aspects of working with nucleic acid therapeutics is that novel interactions can be readily engineered via Watson-Crick base-pairing. Sullenger and co-workers originally selected a factor IXa-specific aptamer that could efficiently inhibit clot formation, then showed that the function of the aptamer could be reversed by an antisense 'antidote' both in vitro and in vivo ${ }^{27,56}$. The aptamer-antidote pair was tested in mouse and porcine model systems ${ }^{107}$, and showed both robust anticoagulation activity and surprisingly rapid reversal of this activity. As the antidote was known to be cleared from the system within minutes, these experiments demonstrate an extraordinarily efficient hybridization of aptamer and antisense in serum. Oligonucleotides have also been used to assemble, rather than inhibit, aptamers. The Sullenger group at Duke University has dimerized an OX40-specific aptamer by hybridization to an oligonucleotide 'organizer' and showed that it behaves as a receptor agonist ${ }^{108,109}$ (FIG. 4a). It may also be possible to generate multimeric aptamer constructs with corresponding avidity effects ${ }^{110}$. When melanoma cancer cells were co-injected into mice together with the aptamer agonist, tumour formation was significantly reduced or delayed. In the future, it is possible that aptamers will use methods associated with nucleic acid computation to act as circulating circuitry networks with combined diagnostic and therapeutic capabilities ${ }^{111}$.

Targeting therapeutics with aptamers. Aptamers that bind to the cell surface can specifically cause therapeutics (such as drugs, toxins or siRNA) to persist in the vicinity of a specific cell or tissue type. This can also potentially 
LNCaP

A prostate cancer-derived cell line with cell-surface prostate-specific membrane antigen.

PC3

A prostate cancer-derived cell line without cell-surface prostate-specific membrane antigen.

PLGA

(Poly(lactic-co-glycolic) acid). PLGA is a controlled-release spontaneously degradable matrix for drugs. cause an increase in the rate of internalization into cells by receptor-mediated endocytosis; for example, by acting as escort molecules to deliver intracellular therapeu$\operatorname{tics}^{112}$. One popular epitope that has been targeted for therapy has been prostate-specific membrane antigen (PSMA), a protein that is widely expressed but rarely found on the cell surface. PSMA is observed on the surface of some prostate cancer cells ${ }^{113,114}$. The Coffey group at Johns Hopkins University School of Medicine, Maryland, USA, selected two aptamers against this receptor, termed $\mathrm{A} 9$ and $\mathrm{A} 10$, that demonstrate low nanomolar $\mathrm{IC}_{50}$ values for this target ${ }^{115}$. As PSMA is constitutively internalized, the PSMA-specific aptamer was also an excellent candidate as an escort aptamer that could mediate delivery via endocytosis.

Conventional small-molecule therapeutics have been delivered by aptamers. Doxorubicin, an anthracycline drug, is widely used for anticancer treatment and is well known to interact with the double helix of DNA. Doxorubicin has been directly bound to the PSMAspecific aptamer A10 and delivered to cells ${ }^{116}$. Other aptamers, including the PTK7-specific sgc $8 \mathrm{c}$, have also been conjugated to doxorubicin and have proved their utility as vectors for drug delivery ${ }^{117}$.

A more innovative application involves the generation of phototoxic aptamers for the targeted therapy of specific cancer cells ${ }^{118}$. DNA aptamers selected against short $O$-glycan peptides specifically expressed only on the surface of cancer cells were modified at their $5^{\prime}$-ends with chlorin e6, a photodynamic agent, and internalized into epithelial tumour cells. Light-activated cytotoxicity relative to the drug alone was found to be enhanced 500 -fold, and resulted in tissue-specific killing of cancer cells.

The delivery of biopolymer therapeutics has also been examined. Gelonin is a toxin that has been conjugated to antibodies or other proteins for delivery to tumour cells, and as it lacks a translocation domain in the absence of conjugation it has little inherent cytotoxicity ${ }^{119}$. Gelonin conjugated to the PSMA-specific aptamer A9 can target and specifically destroy PSMA-overexpressing prostate cancer cells. The conjugates have an increased potency of at least 600 -fold relative to cells that do not express PSMA $^{120}$. Interestingly, studies with both gelonin and drugs have shown that conjugation can reduce the spontaneous uptake of the free therapeutic into non-cancerous cells, and hence potentially reduce side effects.

An interesting recent innovation is the use of aptamers to deliver other oligonucleotide therapeutics such as siRNAs ${ }^{121}$. One of the key difficulties facing the development of siRNA and other RNA therapeutics is their delivery, both systemically and to specific cell or tissue types $^{122,123}$. Several approaches to link PSMA-specific aptamers to siRNA have been reported (FIG. 4b-d). Biotinlabelled aptamers were conjugated to biotin-labelled siRNAs via streptavidin ${ }^{124}$, or aptamers were hybridized to siRNAs ${ }^{125}$. In both instances, specific targeting of siRNAs to $\mathrm{LNCaP}$ cells relative to PC3 cells was observed. The Sullenger group showed that siRNA conjugates could silence two survival genes that are commonly overexpressed in human tumours, polo-like kinase 1 (PLK1) and $B C L-2$. More importantly, intratumoral injections of aptamer-siRNA chimeras into LNCaP xenografts reduced tumour volume, whereas a scrambled aptamer (still bearing the correct siRNA) did not. No interferon response was elicited with aptamer-siRNA constructs, despite the fact that the aptamers contained significant duplex structures. The Giangrande group at the University of Iowa, USA, followed up on these results by further optimizing the aptamer-siRNA chimera ${ }^{126}$. Several standard options for improving siRNA processing were introduced into the original construct, and the identification of a cell line amenable to uptake enabled the demonstration of efficacy after systemic administration $^{126}$.

Aptamer-siRNA chimeras have also been generated by fusing the HIV gp120-specific aptamer and a tat/revspecific siRNA. This construct targets cells infected with HIV-1, and can inhibit HIV replication through both the aptamer and the siRNA components ${ }^{127}$. More aptamers generated against gp120 as well as other HIV proteins such as gp160 may allow for combination aptamer-siRNA delivery therapies ${ }^{128}$.

Finally, aptamers can be used to direct the delivery of supramolecular structures. Using the PSMA-specific aptamer A10, Farokhzad, Langer and their co-workers directed the delivery of nanoparticles to tumour cells ${ }^{129}$. Farokhzad's group further delivered an encapsulated cancer drug, docetaxel, to LNCaP xenografts in nude mice. All seven of the mice treated by intratumoral injection survived and showed reductions in tumour volume, compared with the survival of only four out of seven mice in a control group that was treated with drugencapsulated nanoparticles lacking the PSMA-specific aptamer. Some efficacy was also demonstrated with the chemotherapeutic drug cisplatin delivered to tumour cells via aptamer functionalized PLCA-PEG nanoparticle conjugates $^{130,131}$. Similarly, a nucleolin-specific aptamer was conjugated to a liposome that encased the potent chemotherapeutic cisplatin and led to delivery of the drug to tumours ${ }^{132}$. Furthermore, controlled release of the conjugate to tumours was achieved by using an antisense oligonucleotide. These targeted encapsulation strategies may decrease the systemic toxicity normally associated with chemotherapies.

\section{Summary}

Aptamers represent an interesting class of pharmaceuticals that are intermediate in size, complexity and synthetic accessibility between traditional organic pharmacophores and protein drugs. Aptamers routinely achieve the same affinities and specificities as therapeutic antibodies, avoid the immunogenicity concerns of protein drugs, and can be generated to a range of targets more efficiently than is the case for highthroughput screening methods associated with small molecules.

However, aptamers have not yet demonstrated their place in the therapeutic arena as their high molecular mass and complex syntheses make them more expensive to manufacture than small molecules. Moreover, their still largely unknown pharmacokinetic properties make 
them harder to develop than any given therapeutic antibody. It is hoped that further efforts to reduce the cost of synthesis, to rationally improve pharmacokinetic properties, and to develop approaches to non-antagonist modes of action will improve therapeutic opportunities. It is also true that at some level the relatively small number of therapeutic advances and clinical trials that have been undertaken is a result of the relatively small number of companies that can participate in aptamer development. As the earliest aptamer intellectual property begins to expire, it is anticipated that more companies will join the throng, and among the more promising future possibilities is the emergence of escort aptamers for therapeutic siRNAs to which it is conjugated. In addition, bivalent aptamers that can engage more than one target are emerging, including, for example, the recruitment of a specific cell type to a tumour-associated target, as well as in vivo selections to simultaneously optimize pharmacokinetic properties along with other contributions to drug potency.
Jones, S. et al. Protein-RNA interactions: a structural analysis. Nucleic Acids Res. 29, 943-954 (2001).

2. Jones, S. et al. Protein-DNA interactions: a structural analysis. J. Mol. Biol. 287, 877-896 (1999).

3. Morozova, N. et al. Protein-RNA interactions: exploring binding patterns with a three-dimensional superposition analysis of high resolution structures. Bioinformatics 22, 2746-2752 (2006).

4. Nagai, K. RNA-protein complexes. Curr. Opin. Struct. Biol. 6, 53-61 (1996)

5. Ellington, A. D. \& Szostak, J. W. In vitro selection of RNA molecules that bind specific ligands. Nature 346, 818-822 (1990).

One of the first two publications of the SELEX technique. Aptamers were selected from a random-sequence RNA library against dyes in a proof-of-principle experiment.

6. Tuerk, C. \& Gold, L. Systematic evolution of ligands by exponential enrichment: RNA ligands to bacteriophage T4 DNA polymerase. Science $\mathbf{2 4 9}$ 505-510 (1990)

One of the first two publications of the SELEX technique. One novel and one known aptamer were selected from a randomized loop derived from a known target-binding RNA.

7. Peng, L et al. A combined atomic force/fluorescence microscopy technique to select aptamers in a single cycle from a small pool of random oligonucleotides. Microsc. Res. Tech. 70, 372-381 (2007).

8. Sassanfar, M. \& Szostak, J. W. An RNA motif that binds ATP. Nature 364, 550-553 (1993).

9. Bock, L. C. et al. Selection of single-stranded DNA molecules that bind and inhibit human thrombin. Nature 355, 564-566 (1992).

The first published DNA SELEX experiment and the first published aptamer to a protein target of therapeutic interest.

10. Shamah, S. M., Healy, J. M. \& Cload, S. T. Complex target SELEX. Acc. Chem. Res. 41, 130-138 (2008).

11. Fitter, S. \& James, R. Deconvolution of a complex target using DNA aptamers. J. Biol. Chem. 280, 34193-34201 (2005).

12. Ng, E. W. et al. Pegaptanib, a targeted anti-VEGF aptamer for ocular vascular disease. Nature Rev. Drug Discov. 5, 123-132 (2006).

13. Nissim, A. \& Chernajovsky, Y. Historical development of monoclonal antibody therapeutics. Handb. Exp. Pharmacol. 181, 3-18 (2008).

14. Keefe, A. D. \& Schaub, R. G. Aptamers as candidate therapeutics for cardiovascular indications. Curr. Opin Pharmacol. 8, 147-152 (2008).

15. Lee, J. F., Stovall, G. M. \& Ellington, A. D. Aptamer therapeutics advance. Curr. Opin. Chem. Biol. 10 282-289 (2006)

16. Chen, C. H. et al. Inhibition of heregulin signaling by an aptamer that preferentially binds to the oligomeric form of human epidermal growth factor receptor-3. Proc. Natl Acad. Sci. USA 100, 9226-9231 (2003).

17. Hale, S. P. \& Schimmel, P. Protein synthesis editing by a DNA aptamer. Proc. Natl Acad. Sci. USA 93 2755-2758 (1996).

18. Keefe, A. D. \& Cload, S. T. SELEX with modified nucleotides. Curr. Opin. Chem. Biol. 12, 448-456 (2008).

19. Diener, J. L. et al. Inhibition of von Willebrand factormediated platelet activation and thrombosis by the anti-von Willebrand factor A 1 -domain aptamer ARC1779. J. Thromb. Haemost. 7, 1155-1162 (2009).

20. White, R. R. et al. Inhibition of rat corneal angiogenesis by a nuclease-resistant RNA aptamer specific for angiopoietin-2. Proc. Natl Acad. Sci. USA $100,5028-5033$ (2003)
21. White, R. et al. Generation of species cross-reactive aptamers using "toggle" SELEX. Mol. Ther. 4 567-573 (2001)

22. Jellinek, D. et al. Potent 2'-amino-2'-deoxypyrimidine RNA inhibitors of basic fibroblast growth factor. Biochemistry 34, 11363-11372 (1995).

23. Lin, Y. et al. High-affinity and specific recognition of human thyroid stimulating hormone (hTSH) by in vitroselected 2'-amino-modified RNA. Nucleic Acids Res. 24, 3407-3414 (1996).

24. Lin, Y. et al. Modified RNA sequence pools for in vitro selection. Nucleic Acids Res. 22, 5229-5234 (1994).

25. Biesecker, G. et al. Derivation of RNA aptamer inhibitors of human complement C5. Immunopharmacology 42, 219-230 (1999). Discovery of a C5-specific aptamer that is currently undergoing clinical evaluation as part of a combination therapy for AMD.

26. Ruckman, J. et al. 2'-Fluoropyrimidine RNA-based aptamers to the 165-amino acid form of vascular endothelial growth factor (VEGF165). Inhibition of receptor binding and VEGF-induced vascular permeability through interactions requiring the exon 7-encoded domain. J. Biol. Chem. 273, 20556-20567 (1998).

The discovery and characterization of pegaptanib, a nuclease-resistant aptamer to VEGF and the first aptamer to be approved for clinical use.

27. Rusconi, C. P. et al. RNA aptamers as reversible antagonists of coagulation factor IXa. Nature $\mathbf{4 1 9}$ 90-94 (2002).

Introduction of the strategy that aptamers can be specifically inhibited by complementary oligonucleotides and the demonstration of this principle ex vivo. This aptamer is currently undergoing clinical evaluation.

28. Burmeister, P. E. et al. Direct in vitro selection of a 2'-O-methyl aptamer to VEGF. Chem. Biol. 12, 25-33 (2005)

The first use of the SELEX process to utilize fully modified aptamers with a demonstration of SELEX generating a fully $2^{\prime}-O$-methyl aptamer against VEGF.

29. Burmeister, P. E. et al. 2'-Deoxy purine, 2'-O-methyl pyrimidine $(\mathrm{dRmY})$ aptamers as candidate therapeutics. Oligonucleotides 16, 337-351 (2006)

30. Kang, J. et al. Combinatorial selection of a single stranded DNA thioaptamer targeting TGF- $\beta 1$ protein Bioorg. Med. Chem. Lett. 18, 1835-1839 (2008).

31. Kang, J. et al. Combinatorial selection of a RNA thioaptamer that binds to Venezuelan equine encephalitis virus capsid protein. FEBS Lett. $\mathbf{5 8 1}$, 2497-2502 (2007)

32. King, D. J. et al. Thioaptamer interactions with prion proteins: sequence-specific and non-specific binding sites. J. Mol. Biol. 369, 1001-1014 (2007).

33. Vaught, J. D., Dewey, T. \& Eaton, B. E. T7 RNA polymerase transcription with 5-position modified UTP derivatives. J. Am. Chem. Soc. 126, 11231-11237 (2004)

34. Bilik, K. U. et al. In-vitro and in-vivo antagonistic action of an anti-amylin Spiegelmer. Neuroreport 18, 1855-1859 (2007)

35. Demjen, D. et al. Neutralization of CD95 ligand promotes regeneration and functional recovery after spinal cord injury. Nature Med. 10, 389-395 (2004).

36. Eulberg, D et al. Development of an automated in vitro selection protocol to obtain RNA-based aptamers: identification of a biostable substance $P$ antagonist. Nucleic Acids Res. 33, e45 (2005).

37. Faulhammer, D. et al. Biostable aptamers with antagonistic properties to the neuropeptide nociceptin/orphanin FQ. RNA 10, 516-527 (2004).
38. Helmling, S. et al. Inhibition of ghrelin action in vitro and in vivo by an RNA-Spiegelmer. Proc. Natl Acad. Sci. USA 101, 13174-13179 (2004).

39. Klussman, S., Nolte, A., Bald, R., Erdmann, V. A. \& Furste, J. P. Mirror-image RNA that binds D-adenosine. Nature Biotech. 14, 1112-1115 (1996).

40. Kulkarni, O et al. Spiegelmer inhibition of CCL2/ MCP-1 ameliorates lupus nephritis in MRL-(Fas)Ipr mice. J. Am. Soc. Nephrol. 18, 2350-2358 (2007)

41. Leva, S. et al. GnRH binding RNA and DNA Spiegelmers: a novel approach toward $\mathrm{GnRH}$ antagonism. Chem. Biol 9, 351-359 (2002)

42. Purschke, W. G. et al. An L-RNA-based aquaretic agent that inhibits vasopressin in vivo. Proc. Natl Acad. Sci. USA 103, 5173-5178 (2006)

43. Purschke, W. G. et al. A DNA Spiegelmer to staphylococcal enterotoxin B. Nucleic Acids Res. 31, 3027-3032 (2003).

44. Vater, A. et al. Short bioactive Spiegelmers to migraine-associated calcitonin gene-related peptide rapidly identified by a novel approach: tailored-SELEX Nucleic Acids Res. 31, e130 (2003)

45. Caruthers, M. H. Gene synthesis machines: DNA chemistry and its uses. Science 230, 281-285 (1985)

46. Healy, J. M. et al. Pharmacokinetics and biodistribution of novel aptamer compositions. Pharm. Res. 21, 2234-2246 (2004).

47. Griffin, L. C. et al. In vivo anticoagulant properties of a novel nucleotide-based thrombin inhibitor and demonstration of regional anticoagulation in extracorporeal circuits. Blood 81, 3271-3276 (1993).

48. Uhlmann, E. et al. Use of minimally modified antisense oligonucleotides for specific inhibition of gene expression. Methods Enzymol. 313, 268-284 (2000).

49 Adler A et al Post-SELEX chemical optimization of a trypanosome-specific RNA aptamer. Comb. Chem. High Throughput Screen. 11, 16-23 (2008).

50. Floege, J. et al. Novel approach to specific growth factor inhibition in vivo: antagonism of platelet-derived growth factor in glomerulonephritis by aptamers. Am. J. Pathol. 154, 169-179 (1999).

51. Beigelman, L. et al. Synthesis and biological activities of a phosphorodithioate analog of $2^{\prime}$ 5'-oligoadenylate. Nucleic Acids Res. 23, 3989-3994 (1995).

52. Kawaguchi, T. et al. Stability, specific binding activity, and plasma concentration in mice of an oligodeoxynucleotide modified at 5 '-terminal with poly(ethylene glycol). Biol. Pharm. Bull. 18, 474-476 (1995).

53. Watson, S. R. et al. Anti--L-selectin aptamers: binding characteristics, pharmacokinetic parameters, and activity against an intravascular target in vivo. Antisense Nucleic Acid Drug Dev. 10, 63-75 (2000).

54. Fontana, D. J., Epstein, D. E. \& Wilson, C. RNA as the drug discovery tool. 1. Aptamer drug development. 5) Aptamer therapeutics. Idenshi Igaku Mook 4, 61-70 (2006).

55. Soutschek, J. et al. Therapeutic silencing of an endogenous gene by systemic administration of modified siRNAs. Nature 432, 173-178 (2004).

56. Rusconi, C. P. et al. Antidote-mediated control of an anticoagulant aptamer in vivo. Nature Biotech. 22 1423-1428 (2004).

57. Hu, T. M. \& Hayton, W. L. Allometric scaling of xenobiotic clearance: uncertainty versus universality. AAPS PharmSci. 3, e29 (2001)

58. Armstrong, J. K. et al. Antibody against poly(ethylene glycol) adversely affects PEG-asparaginase therapy in acute lymphoblastic leukemia patients. Cancer 110 103-111 (2007) 
59. Farman, C. A. \& Kornbrust, D. J. Oligodeoxynucleotide studies in primates: antisense and immune stimulatory indications. Toxicol. Pathol. 31 (Suppl.), 119-122 (2003)

60. Henry, S. P. et al. Complement activation is responsible for acute toxicities in rhesus monkeys treated with a phosphorothioate oligodeoxynucleotide. Int. Immunopharmacol. 2, 1657-1666 (2002).

61. Marquis, J. K. \& Grindel, J. M. Toxicological evaluation of oligonucleotide therapeutics. Curr. Opin. Mol. Ther 2, 258-263 (2000).

62. Yu, D. et al. Modifications incorporated in $\mathrm{CpG}$ motifs of oligodeoxynucleotides lead to antagonist activity of Toll-like receptors 7 and 9. J. Med. Chem. 52 , 5108-5114 (2009).

63. Cooper, C. L. et al. Immunostimulatory effects of three classes of $\mathrm{CpG}$ oligodeoxynucleotides on PBMC from HCV chronic carriers. J. Immune Based Ther. Vaccines 6, 3 (2008).

64. Krieg, A. M. Therapeutic potential of Toll-like receptor 9 activation. Nature Rev. Drug Discov. 5, 471-484 (2006).

65. Krieg, A. M. Toll-like receptor 9 (TLR9) agonists in the treatment of cancer. Oncogene 27, 161-167 (2008).

66. Sheehan, J. P. \& Lan, H. C. Phosphorothioate oligonucleotides inhibit the intrinsic tenase complex. Blood 92, 1617-1625 (1998).

67. Goebl, N. et al. Development of a sensitive and specific in situ hybridization technique for the cellular localization of antisense oligodeoxynucleotide drugs in tissue sections. Toxicol. Pathol. 35, 541-548 (2007).

68. Henry, S. P. et al. in Antisense Drug Technology, Principles, Strategies, and Applications 2nd edn Ch. 12 (ed. Crooke, S.) 327-364 (Taylor and Francis, Boca Raton, Florida, 2008)

69. Gragoudas, E. S. et al. Pegaptanib for neovascular age-related macular degeneration. N. Engl. J. Med. 351, 2805-2816 (2004)

70. Chakravarthy, U. et al. Year 2 efficacy results of 2 randomized controlled clinical trials of pegaptanib for neovascular age-related macular degeneration. Ophthalmology 113, e1-e25 (2006).

71. Bates, P. J. et al. Discovery and development of the G-rich oligonucleotide AS1411 as a novel treatmen for cancer. Exp. Mol. Pathol. 86, 151-164 (2009).

72. Bates, P. J. et al. Antiproliferative activity of G-rich oligonucleotides correlates with protein binding. J. Biol. Chem. 274, 26369-26377 (1999).

73. Soundararajan, S. et al. The nucleolin targeting aptamer AS1411 destabilizes Bcl-2 messenger RNA in human breast cancer cells. Cancer Res. 68 , 2358-2365 (2008).

74. Teng, Y. et al. AS1411 alters the localization of a complex containing protein arginine methyltransferase 5 and nucleolin. Cancer Res. 67, 10491-10500 (2007).

75. Girvan, A C et al AGRO100 inhibits activation of

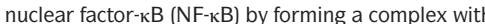
NF-kB essential modulator (NEMO) and nucleolin. Mol. Cancer Ther. 5, 1790-1799 (2006).

76. AntiSoma. Press Release 16/12/2009. AS 1411 shows activity in kidney cancer but AML remains priority. Antisoma website [online], http://www.antisoma.com/asm/media/press/ pr2009/2009-12-16/ (2009).

77. Chan, M. Y. et al. A randomized, repeat-dose pharmacodynamic and safety study of an antidotecontrolled factor IXa inhibitor. J. Thromb. Haemost. 6, 789-796 (2008).

78. Chan, M. Y. et al. Phase $1 \mathrm{~b}$ randomized study of antidote-controlled modulation of factor IXa activity in patients with stable coronary artery disease. Circulation 117, 2865-2874 (2008).

79. Huang, R.-H. et al. Crystal structure of von Willebrand factor (VWF) A1 domain in complex with aptamer ARC1172, an inhibitor of VWF-platelet binding. Blood (ASH Annual Meeting Abstracts) 112, Abstract 257 (2008).

80. Gilbert, J. C. et al. First-in-human evaluation of anti von Willebrand factor therapeutic aptamer ARC 1779 in healthy volunteers. Circulation 116, 2678-2686 (2007).

Phase I clinical evaluation of ARC1779, a von Willebrand factor-specific aptamer that was driven to bind the A1 domain of the target by toggling between different target forms during SELEX.

81. Waters, E. K. et al. Effect of NU172 and bivalirudin on ecarin clotting time in human plasma and whole blood. J. Thromb. Haemost. 7, 683 (2009).
82. Mullins, R. F. et al. Drusen associated with aging and age-related macular degeneration contain proteins common to extracellular deposits associated with atherosclerosis, elastosis, amyloidosis, and dense deposit disease. FASEB J. 14, 835-846 (2000).

83. Green, L. S. et al. Inhibitory DNA ligands to plateletderived growth factor B-chain. Biochemistry 35 , 14413-14424 (1996)

Discovery of a PDGF-specific aptamer that is currently undergoing clinical evaluation as part of a combination therapy for AMD.

84. Sayyed, S. G. et al. Podocytes produce homeostatic chemokine stromal cell-derived factor-1/CXCL12, which contributes to glomerulosclerosis, podocyte loss and albuminuria in a mouse model of type 2 diabetes. Diabetologia 52, 2445-2454 (2009).

85. Kulkarni, O. et al. Anti-Ccl2 Spiegelmer permits 75\% dose reduction of cyclophosphamide to control diffuse proliferative lupus nephritis and pneumonitis in MRLFas(lpr) mice. J. Pharmacol. Exp. Ther. 328, 371-377 (2009)

86. Maasch, C. et al. Physicochemical stability of NOX-E36, a 40mer L-RNA (Spiegelmer) for therapeutic applications. Nucleic Acids Symp. Ser. (Oxf.) 52, 61-62 (2008)

87. Ninichuk, V. et al. Late onset of $\mathrm{Cl} 2$ blockade with the Spiegelmer mNOX-E36-3'PEG prevents glomerulosclerosis and improves glomerular filtration rate in $d b / d b$ mice. Am. J. Pathol. 172, 628-637 (2008)

Demonstration of activity in an animal model of a CCL2-specific Spiegelmer (mirror-image aptamer) that is currently being evaluated in the clinic as a treatment for complications of type $\mathbf{2}$ diabetes.

88. Cox, J. C., Rudolph, P. \& Ellington, A. D. Automated RNA selection. Biotechnol. Prog. 14, 845-850 (1998).

89. Cox, J. C. \& Ellington, A. D. Automated selection of anti-protein aptamers. Bioorg. Med. Chem. 9 2525-2531 (2001)

90. Cox, J. C. et al. Automated selection of aptamers against protein targets translated in vitro: from gene to aptamer. Nucleic Acids Res. 30, e108 (2002)

91. Lou, X. et al. Micromagnetic selection of aptamers in microfluidic channels. Proc. Natl Acad. Sci. USA 106, 2989-2994 (2009).

92. Qian, J. et al. Generation of highly specific aptamers via micromagnetic selection. Anal. Chem. 81 5490-5495 (2009).

93. Ostroff, R. et al. The stability of the circulating human proteome to variations in sample collection and handling procedures measured with an aptamerbased proteomics array. J. Proteomics 73, 649-666 (2009)

Study showcasing the achievements of Somalogic in the generation of aptamers to several hundred different protein targets.

94. Gugliotti, L. A., Feldheim, D. L. \& Eaton, B. E. RNA-mediated metal-metal bond formation in the synthesis of hexagonal palladium nanoparticles. Science 304, 850-852 (2004).

95. Tarasow, T. M., Tarasow, S. L. \& Eaton, B. E. RNA-catalysed carbon-carbon bond formation. Nature 389, 54-57 (1997).

96. Wiegand, T. W., Janssen, R. C. \& Eaton, B. E. Selection of RNA amide synthases. Chem. Biol. 4 , 675-683 (1997)

97. Hormozdiari, F. et al. Combinatorial algorithms for structural variation detection in high-throughput sequenced genomes. Genome Res. 19, 1270-1278 (2009).

98. Chushak, Y. \& Stone, M. O. In silico selection of RNA aptamers. Nucleic Acids Res. 37, e87 (2009).

99. Cerchia, L. et al. Cell-specific aptamers for targeted therapies. Methods Mol. Biol. 535, 59-78 (2009).

100. Shangguan, D. et al. Identification of liver cancerspecific aptamers using whole live cells. Anal. Chem. 80, 721-728 (2008).

101. Daniels, D. A. et al. A tenascin-C aptamer identified by tumor cell SELEX: systematic evolution of ligands by exponential enrichment. Proc. Natl Acad. Sci. USA 100, 15416-15421 (2003). An early example of cell SELEX in which selection was performed against a monolayer of living tumour-derived cells with the target identification occurring once SELEX was complete.

102. Li, N. et al. Technical and biological issues relevan to cell typing with aptamers. J. Proteome. Res. 8 , 2438-2448 (2009)

103. Li, N. et al. Directed evolution of gold nanoparticle delivery to cells. Chem. Commun. (Camb.) 46 392-394 (2010).
104. Mallikaratchy, P. et al. Using aptamers evolved from cell-SELEX to engineer a molecular delivery platform. Chem. Commun. (Camb.) 3056-3058 (2009).

105. Homann, M. \& H. U. Goringer, Combinatorial selection of high affinity RNA ligands to live African trypanosomes. Nucleic Acids Res. 27, 2006-2014 (1999).

106. Mi, J. et al. In vivo selection of tumor-targeting RNA motifs. Nature Chem. Biol. 6, 22-24.

107. Nimjee, S. M. et al. A novel antidote-controlled anticoagulant reduces thrombin generation and inflammation and improves cardiac function in cardiopulmonary bypass surgery. Mol. Ther. 14 408-415 (2006).

108. Dollins, C. M et al. Assembling OX40 aptamers on a molecular scaffold to create a receptor-activating aptamer. Chem. Biol. 15, 675-682 (2008).

109. Zhou, J. \& Rossi, J. J. Bivalent aptamers deliver the punch. Chem. Biol. 15, 644-645 (2008).

110. Yan, A. C. \& Levy, M. Aptamers and aptamer targeted delivery. RNA Biol. 6, 316-320 (2009).

111. Benenson, Y. et al. An autonomous molecular computer for logical control of gene expression. Nature 429, 423-429 (2004).

112. Hicke, B. J. \& Stephens, A. W. Escort aptamers: a delivery service for diagnosis and therapy. J. Clin Invest. 106, 923-928 (2000)

113. Chang, S. S. Overview of prostate-specific membrane antigen. Rev. Urol. 6 (Suppl.) 10, 13-18 (2004).

114. Chang, S. S. \& Heston, W. D. The clinical role of prostate-specific membrane antigen (PSMA) Urol. Oncol. 7, 7-12 (2002).

115. Lupold, S. E. et al. Identification and characterization of nuclease-stabilized RNA molecules that bind human prostate cancer cells via the prostate-specific membrane antigen. Cancer Res. 62, 4029-4033 (2002).

116. Bagalkot, V. et al. An aptamer-doxorubicin physical conjugate as a novel targeted drug-delivery platform. Angew. Chem. Int. Ed. Engl 45 8149-8152 (2006).

117. Huang, Y. F. et al. Molecular assembly of an aptamer-drug conjugate for targeted drug delivery to tumor cells. Chembiochem 10, 862-868 (2009).

118. Ferreira, C. S. et al. Phototoxic aptamers selectively enter and kill epithelial cancer cells. Nucleic Acids Res. 37, 866-876 (2009)

119. Better, M. et al. Gelonin analogs with engineered cysteine residues form antibody immunoconjugates with unique properties. J. Biol. Chem. 269. 9644-9650 (1994).

120. Chu, T. C. et al. Aptamer:toxin conjugates that specifically target prostate tumor cells. Cancer Res. 66, 5989-5992 (2006)

121. Cullen, B. R. RNA interference: antiviral defense and genetic tool. Nature Immunol. 3, 597-599 (2002).

122. Sioud, M. On the delivery of small interfering RNAs into mammalian cells. Expert Opin. Drug Deliv. 2, 639-651 (2005)

123. Xie, F. Y., Woodle, M. C. \& Lu, P. Y. Harnessing in vivo siRNA delivery for drug discovery and therapeutic development. Drug Discov. Today 11, 67-73 (2006)

124. Chu, T. C. et al. Aptamer mediated siRNA delivery. Nucleic Acids Res. 34, e73 (2006).

125. McNamara, J. O. 2nd et al. Cell type-specific delivery of siRNAs with aptamer-siRNA chimeras. Nature Biotech. 24, 1005-1015 (2006)

126. Dassie, J. P. et al. Systemic administration of optimized aptamer-siRNA chimeras promotes regression of PSMA-expressing tumors. Nature Biotech. 27, 839-849 (2009). First demonstration of antitumour activity in a mouse xenograft model with the systemic delivery of an aptamer-targeted siRNA conjugate.

127. Zhou, J. et al. Novel dual inhibitory function aptamersiRNA delivery system for HIV-1 therapy. Mol. Ther. 16, 1481-1489 (2008). Demonstration of activity in vivo for a HIV-specific siRNA conjugated to a gp120-specific aptamer that enables the targeting of infected cells.

128. Zhou, J. et al. Selection, characterization and application of new RNA HIV gp 120 aptamers for facile delivery of Dicer substrate siRNAs into HIV infected cells. Nucleic Acids Res. 37, 3094-3109 (2009).

129. Farokhzad, O. C. et al. Nanoparticle-aptamer bioconjugates: a new approach for targeting prostate cancer cells. Cancer Res. 64, 7668-7672 (2004).

130. Dhar, S. et al. Targeted delivery of cisplatin to prostate cancer cells by aptamer functionalized Pt(IV) prodrug-PLGA-PEG nanoparticles. Proc. Natl Acad. Sci. USA 105, 17356-17361 (2008). 
131. Gu, F. et al. Precise engineering of targeted nanoparticles by using self-assembled biointegrated block copolymers. Proc. Natl Acad. Sci. USA 105 2586-2591 (2008).

132. Cao, Z. et al. Reversible cell-specific drug delivery with aptamer-functionalized liposomes. Angew. Chem. Int Ed. Engl. 48, 6494-6498 (2009).

133. Guo, K. T. et al. CELL-SELEX: novel perspectives of aptamer-based therapeutics. Int. J. Mol. Sci. 9 668-678 (2008)

134. Tuerk, C., MacDougal, S. \& Gold, L. RNA pseudoknots that inhibit human immunodeficiency virus type 1 reverse transcriptase. Proc. Natl Acad. Sci. USA 89 6988-6992 (1992).

135. Giver, L. et al. Selection and design of high-affinity RNA ligands for HIV-1 Rev. Gene, 137, 19-24 (1993).

136. Jellinek, D. et al. High-affinity RNA ligands to basic fibroblast growth factor inhibit receptor binding. Proc. Natl Acad. Sci. USA 90, 11227-11231 (1993).

137. Pan, W. et al. Isolation of virus-neutralizing RNAs from a large pool of random sequences. Proc. Natl Acad. Sci. USA 92, 11509-11513 (1995).

138. Allen, P., Worland, S. \& Gold, L. Isolation of highaffinity RNA ligands to HIV-1 integrase from a random pool. Virology 209, 327-336 (1995).

139. Green, L. S. et al. Nuclease-resistant nucleic acid ligands to vascular permeability factor/vascular endothelial growth factor. Chem. Biol. 2, 683-695 (1995).

140. Wiegand, T. W. et al. High-affinity oligonucleotide ligands to human IgE inhibit binding to Fc epsilon receptor I. J. Immunol. 157, 221-230 (1996).

141. O'Connell, D. et al. Calcium-dependent oligonucleotide antagonists specific for L-selectin. Proc. Natl Acad. Sci. USA 93, 5883-5887 (1996).

142. Lee, S. W. \& Sullenger, B. A. Isolation of a nucleaseresistant decoy RNA that can protect human acetylcholine receptors from myasthenic antibodies. Nature Biotech. 15, 41-45 (1997).

143. Kubik, M. F et al. Isolation and characterization of 2'-fluoro-, 2'-amino-, and 2'-fluoro-/amino-modified RNA ligands to human IFN- $\gamma$ that inhibit receptor binding. J. Immunol. 159, 259-267 (1997).

144. Pagratis, N. C. et al. Potent 2'-amino-, and 2'-fluoro-2'deoxyribonucleotide RNA inhibitors of keratinocyte growth factor. Nature Biotech. 15, 68-73 (1997).

145. Charlton, J., Sennello, J. \& Smith, D. In vivo imaging of inflammation using an aptamer inhibitor of human neutrophil elastase. Chem. Biol. 4, 809-816 (1997).

146. Jenison, R. D. et al. Oligonucleotide inhibitors of P-selectin-dependent neutrophil-platelet adhesion. Antisense Nucleic Acid Drug Dev. 8, 265-279 (1998).
147. Ulrich, H. et al. In vitro selection of RNA molecules that displace cocaine from the membrane-bound nicotinic acetylcholine receptor. Proc. Natl Acad. Sci. USA 95, 14051-14056 (1998)

148. Bridonneau, P. et al. High-affinity aptamers selectively inhibit human nonpancreatic secretory phospholipase A2 (hnps-PLA2). J. Med. Chem. 41, 778-786 (1998).

149. Bell, S. D. et al. RNA molecules that bind to and inhibit the active site of a tyrosine phosphatase. J. Biol Chem. 273, 14309-14314 (1998)

150. Gal, S. W. et al. Selection of a RNA aptamer that binds to human activated protein $\mathrm{C}$ and inhibits its protease function. Eur. J. Biochem. 252, 553-562 (1998).

151. Kraus, E., James, W. \& Barclay, A. N. Cutting edge novel RNA ligands able to bind CD4 antigen and inhibit $\mathrm{CD}^{+}{ }^{+} \mathrm{T}$ lymphocyte function. J. Immunol. 160, 5209-5212 (1998)

152. Lebruska, L. L. \& Maher, L. J. 3rd. Selection and characterization of an RNA decoy for transcription factor NF-kB. Biochemistry 38, 3168-3174 (1999).

153. Blind, M., Kolanus, W. \& Famulok, M. Cytoplasmic RNA modulators of an inside-out signal-transduction cascade. Proc. Natl Acad. Sci. USA 96, 3606-3610 (1999).

154. Mayer, G. et al. Controlling small guanine-nucleotide exchange factor function through cytoplasmic RNA intramers. Proc. Natl Acad. Sci. USA 98, 4961-4965 (2001).

155. Ruckman. J., Gold, L., Stephens. A. \& Janjic, N Nucleic acid ligands to integrins. US Patent 7,094,535 (2006)

156. Mi, J. et al. Targeted inhibition of $\alpha v \beta 3$ integrin with an RNA aptamer impairs endothelial cell growth and survival. Biochem. Biophys. Res. Commun. 338, 956-963 (2005)

157. Hicke, B. J. et al. Tenascin-C aptamers are generated using tumor cells and purified protein. J. Biol. Chem. 276, 48644-48654 (2001).

158. Martell, R. E., Nevins, J. R. \& Sullenger, B. A Optimizing aptamer activity for gene therapy applications using expression cassette SELEX Mol. Ther. 6, 30-34 (2002).

159. Daniels, D. A. et al. Generation of RNA aptamers to the G-protein-coupled receptor for neurotensin, NTS-1. Anal. Biochem. 305, 214-226 (2002).

160. Sekiya, S. et al. Structure/function analysis of an RNA aptamer for hepatitis C virus NS3 protease. J. Biochem. 133, 351-359 (2003).

161. Khati, M. et al. Neutralization of infectivity of diverse R5 clinical isolates of human immunodeficiency virus type 1 by gp 120 -binding 2'F-RNA aptamers. J. Virol. 77, 12692-12698 (2003).
162. Santulli-Marotto, S. et al. Multivalent RNA aptamers that inhibit CTLA-4 and enhance tumor immunity. Cancer Res. 63, 7483-7489 (2003).

163. Theis, M. G. et al. Discriminatory aptamer reveals serum response element transcription regulated by cytohesin-2. Proc. Natl Acad. Sci. USA 101 11221-11226 (2004).

164. Marro, M. L. et al. Identification of potent and selective RNA antagonists of the IFN- $\gamma$-inducible CXCL10 chemokine. Biochemistry 44, 8449-8460 (2005)

165. Cerchia, L. et al. Neutralizing aptamers from whole cell SELEX inhibit the RET receptor tyrosine kinase. PLoS Biol. 3, e123 (2005)

166. Ferreira, C. S., Matthews, C. S. \& Missailidis, S. DNA aptamers that bind to MUC1 tumour marker: design and characterization of MUC 1-binding single-stranded DNA aptamers. Tumour Biol. 27, 289-301 (2006).

167. White, R. R. et al. A nuclease-resistant RNA aptamer specifically inhibits angiopoietin-1-mediated Tie2 activation and function. Angiogenesis 11, 395-401 (2008).

168. Murakami, K. et al. Anti-bovine prion protein RNA aptamer containing tandem GGA repeat interacts both with recombinant bovine prion protein and its beta isoform with high affinity. Prion 2, 73-80 (2008).

169. Blake, C. M. et al. Antimetastatic potential of PAl-1-specific RNA aptamers. Oligonucleotides 19 117-128 (2009)

170. Liu, Y. et al. Aptamers selected against the unglycosylated EGFRvIII ectodomain and delivered intracellularly reduce membrane-bound EGFRvIII and induce apoptosis. Biol. Chem. 390, 137-144 (2009).

\section{Acknowledgements}

This work was supported in part by the Welch Foundation (Grant Number F-1654) Award Number R01GM077040 from the National Institute of General Medical Sciences. The content is solely the responsibility of the authors and does not necessarily represent the official views of the National Institute of General Medical Sciences or the National Institutes of Health.

\section{Competing interests statement}

The authors declare competing financial interests: see web version for details.

FURTHER INFORMATION

Laboratory of Andrew Ellington: http://ellingtonlab.org Prescribing information for pegaptanib sodium (Macugen): http://www.macugen.com/macugenUSPI.pdf ALL LINKS ARE ACTIVE IN THE ONLINE PDF 